\title{
Comparative Phenotyping of Two Commonly Used Chlamydomonas reinhardtii Background Strains: CC-1690 (21gr) and CC-5325 (the CLiP Mutant Library Background)
}

Ningning Zhang1,\#, Leila Pazouki ${ }^{1, \#}$, Huong Nguyen ${ }^{1, \#}$, Sigrid Jacobshagen², Ming Xia ${ }^{1}$, Anastasiya Klebanovych ${ }^{1}$, Kirk J. Czymmek ${ }^{1}$, Ru Zhang ${ }^{1, *}$

\# Equal contribution

* Corresponding author: Ru Zhang (rzhang@danforthcenter.org)

${ }^{1}$ Donald Danforth Plant Science Center, St. Louis, Missouri 63132, USA.

${ }^{2}$ Western Kentucky University, Bowling Green, Kentucky 42101, USA.

\begin{abstract}
The unicellular green alga Chlamydomonas reinhardtii is an excellent model organism to investigate many essential cellular processes in photosynthetic eukaryotes. Two commonly used background strains of Chlamydomonas are CC-1690 and CC-5325. CC1690, also called $21 \mathrm{gr}$, has been used for the Chlamydomonas genome project and several transcriptome analyses. $\mathrm{CC}-5325$ is the background strain for the Chlamydomonas Library Project (CLiP). Photosynthetic performance in CC-5325 has not been evaluated in comparison with CC-1690. Additionally, CC-5325 is often considered to be cell-wall deficient, although detailed analysis is missing. The circadian rhythms in CC-5325 are also unclear. To fill these knowledge gaps and facilitate the use of the CLiP mutant library for various screens, we performed phenotypic comparisons between CC1690 and CC-5325. Our results showed that CC-5325 grew faster heterotrophically in dark and equally well in mixotrophic liquid medium as compared to CC-1690. CC-5325 had lower photosynthetic efficiency and was more sensitive to heat than CC-1690. Furthermore, CC-5325 had an intact cell wall with comparable integrity to that in CC-1690, though appears to have reduced thickness. Finally, CC-5325 could perform phototaxis, but could not maintain a sustained circadian rhythm of phototaxis as CC160 did. Our results will be useful for researchers in the Chlamydomonas community to choose suitable background strains for mutant analysis and employ the CLiP mutant library for genome-wide mutant screens under appropriate conditions, especially in the areas of photosynthesis, thermotolerance, cell wall, and circadian rhythms.
\end{abstract}

\section{Keywords}

Chlamydomonas reinhardtii; CC-1690; CC-5325; Chlamydomonas Library Project (CLiP); photosynthesis; heat tolerance; cell wall; circadian rhythm of phototaxis.

\section{Introduction}

The unicellular green alga Chlamydomonas reinhardtii (Chlamydomonas throughout) is a superior model organism to study important cellular processes in photosynthetic eukaryotes, including but not limited to: photosynthesis (Minagawa and Tokutsu, 2015), cell cycle (Cross and Umen, 2015), lipid accumulation (Li-Beisson et al., 2015), stress responses (Erickson et al., 2015; Schroda et al., 2015), and biofuel production (Scranton et al., 2015). Chlamydomonas has several advantages that can be leveraged: (1) Vegetative cells are haploid, therefore mutant phenotypes present easily; (2) Cells grow quickly with 6 8 h doubling time under normal growth conditions; (3) Cells grow in light 
using photosynthesis but also in dark with a supplied carbon source, allowing for maintenance of photosynthetic mutants in the dark; (4) All three genomes (nucleus, chloroplast, mitochondrion) of Chlamydomonas are sequenced and transformable, making it an excellent model to study inter-organellar communications (Maul et al., 2002; Merchant et al., 2007; Gallaher et al., 2018); (5) It has generally smaller gene families than land plants, simplifying genetic and functional analyses (Merchant et al., 2007; Karpowicz et al., 2011); and (6) Many cellular processes in Chlamydomonas have similarities with land plants, making it an excellent model organism to identify novel genes/pathways with potential applications in crops.

Chlamydomonas has rich genetic and genomic resources, and its unicellular nature enables high-throughput approaches and functional genomics. Many transcriptomic analyses under various conditions exist in Chlamydomonas (Salomé and Merchant, 2021), including light stress (Mettler et al., 2014), nutrient limitation (González-Ballester et al., 2010; Schmollinger et al., 2014; Park et al., 2015), metal deficiency (Urzica et al., 2012; Blaby-Haas et al., 2016), day/night cycle (Zones et al., 2015; Strenkert et al., 2019), oxidative stress (Blaby et al., 2015), and temperature stresses (Légeret et al., 2016; Li et al., 2020; Zhang et al., 2021). Additionally, several proteomics datasets for specific cellular structures are available, including chloroplasts (Terashima et al., 2011), pyrenoids (Mackinder et al., 2016; Zhan et al., 2018), mitochondria (Atteia et al., 2009), and others. Two powerful and efficient gene cloning approaches are well-established in Chlamydomonas: the Moclo Toolkit (Golden Gate cloning kit for synthetic biology) (Crozet et al., 2018) and the recombineering pipeline to clone large and complex genes (EmrichMills et al., 2021). Furthermore, a genome-saturating, indexed, mapped Chlamydomonas mutant library is available for both reverse and forward genetic screens (Chlamydomonas Library Project, CLiP, https://www.chlamylibrary.org/) (Li et al., 2016, 2019). The mutant library also allows for high-throughput, quantitative phenotyping of genome-wide mutants in pooled cultures under different conditions (Li et al., 2019; Vilarrasa-Blasi et al., 2020). The mutant library is maintained and distributed by the Chlamydomonas Resource Center at the University of Minnesota, which also has several other collections of mutants in Chlamydomonas (https://www.chlamycollection.org/). Additionally, highly efficient insertional mutagenesis and CRISPR gene editing tools are well-optimized in Chlamydomonas (Shimogawara et al., 1998; Wang et al., 2019; Greiner et al., 2017; Dhokane et al., 2020; Picariello et al., 2020). These resources and tools accelerate research using Chlamydomonas as a model organism.

Two commonly used Chlamydomonas background strains are CC-1690 and CC-5325.

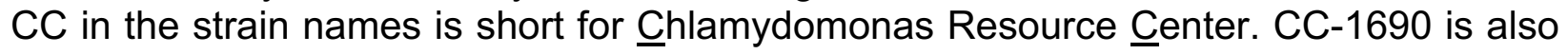
called $21 \mathrm{gr}$ or Sager $21 \mathrm{gr}$ because it was from Ruth Sager at the Sidney Farber Cancer Institute in 1983 (Sager, 1955; Pröschold et al., 2005). CC-1690 is mating type plus (mt ${ }^{+}$) and has been used for most of the cDNA libraries and subsequent EST sequences, and the Chlamydomonas Genome Project (Shrager et al., 2003). Its genome has been sequenced multiple times by several laboratories (Gallaher et al., 2015; Flowers et al., 2015). It has also been used for several transcriptome analyses (Mettler et al., 2014; Zhang et al., 2021) and is an often-preferred background strain for photosynthesis- or stress-related experiments (Mackinder et al., 2016; Yamano et al., 2021; Zachleder et al., 
2019; Ivanov et al., 2021). CC-5325 is relatively new, available to the Chlamydomonas community since 2014 (Zhang et al., 2014), but has been frequently used because it is the background strain of the Chlamydomonas Library Project (CLiP, https://www.chlamylibrary.org) (Li et al., 2016, 2019). CC-5325 is mating type minus ( $\mathrm{mt}^{-}$) and it is the same as CC-4533, which was from an independent cryogenic storage copy. CC-5325 is also called CMJ030 (the $\underline{30}^{\text {th }}$ select Chlamydomonas strain from the laboratory of Dr. Martin Jonikas). CC-5325 was isolated from a cross between two parental strains: $4 \overline{\mathrm{A}}^{-}$(cell wall intact) and $\mathrm{D}^{2} 6^{+}$(cell wall deficient). This particular strain was chosen as the background strain of the CLiP mutant library because of its several desirable features (Zhang et al., 2014; Li et al., 2016): it recovers well from cryogenic storage, has high electroporation and mating efficiencies, grows efficiently in heterotrophic and photoautotrophic conditions, has a functional carbon concentrating mechanism (CCM) and low clumping in liquid culture, swims normally, and has minimal adherence to glass. Since 2015, more than 500 scientific papers have been published using CC-5325 or mutants in its background, for example (Mackinder et al., 2016; Chaux et al., 2017; Itakura et al., 2019; Mukherjee et al., 2019; Perlaza et al., 2019; He et al., 2020; Amiya and Shapira, 2021). Genome-wide mutant screens have been performed under diverse growth conditions by using the Chlamydomonas CLiP mutant library ( $\mathrm{Li}$ et al., 2019; Vilarrasa-Blasi et al., 2020).

Despite its widespread use, some questions regarding CC-5325 remain. Although a genome-wide screen for mutants deficient in photosynthesis was performed by using the CLiP mutant library (Li et al., 2019), detailed analysis of photosynthesis in CC-5325, the CLiP background, is rare. Chaux et al. reported some photosynthetic measurements in CC-5325 when characterizing a CLiP mutant with deficiency in the light reaction of photosynthesis (Chaux et al., 2017). However, photosynthesis in CC-5325 has not been thoroughly evaluated by comparing with other commonly used laboratory strains, such as CC-1690. This information will be helpful for employing the CLiP mutant library to study mutants deficient in photosynthesis. Additionally, because one parent strain of CC-5325, $\mathrm{D} 66^{+}$, is cell-wall deficient, CC-5325 is often referred to as a cell-wall deficient strain and the Chlamydomonas Resource Center labels it with cw15 for cell wall deficiency. The name of cw15 comes from a cell-wall deficient mutant, in which the cell wall is absent or greatly reduced as compared to wildtype (Davies and Plaskitt, 1971; Hyams and Davies, 1972). Consequently, to eliminate the effects of cell wall deficiency, researchers often cross CLiP mutants in the CC-5325 background to other cell-wall intact strains for further analysis. However, the integrity of the cell wall in CC-5325 has not been carefully investigated. Furthermore, among the 121 different conditions for genome-wide Chlamydomonas mutant screens using the CLiP mutant library, screens related to circadian rhythms are lacking (Vilarrasa-Blasi et al., 2020). It is unclear if CC-5325 displays normal circadian rhythms and how well it can maintain its circadian rhythms.

To address these questions mentioned above, we performed and compared the phenotypic analyses in CC-1690 and CC-5325. Our results showed that: (1) CC-5325 had lower photosynthetic efficiency than CC-1690, but it grew better than CC-1690 in dark conditions, suggesting $\mathrm{CC}-5325$ is a suitable backgrounds strain for mutants deficient in photosynthesis; (2) CC-5325 was more heat sensitive than CC-1690; (3) CC- 
5325 had an intact cell wall with comparable integrity to that in CC-1690, except that the cell wall in CC-5325 appeared thinner than that in CC-1690; (4) CC-1690 could maintain robust circadian rhythm of phototaxis in either constant darkness or constant light, but CC-5325 could not. In this work, we focused on specific phenotypes related to photosynthesis, thermotolerance, and circadian rhythm of phototaxis in these two strains. We believe our results will be useful for the Chlamydomonas community to better understand the differences between these two commonly used background strains, especially CC-5325 as the background of the CLiP mutant library.

\section{Results}

We grew Chlamydomonas strains CC-1690 and CC-5325 in photobioreactors (PBRs) under well-controlled conditions. Under the same cultivation conditions in PBRs, these two strains had different cell shapes and sizes (Figure 1). CC-5325 had larger cell volume than CC-1690. Despite these morphological differences, both had comparable growth rates, as estimated by the rate of increased $\mathrm{OD}_{680}$ or chlorophyll content (Figure 2).

We next evaluated pigment content using algal cultures of CC-1690 and CC-5325 grown under well-controlled conditions in PBRs as mentioned above. CC-5325 had more chlorophyll and carotenoids per cell than CC-1690, but the differences were mainly due to the larger cell volume of CC-5325, as these two strains had no differences in pigments per cell volume (Figure 3a-d). Both strains had the same chlorophyll a/b ratio (Figure 3e). However, CC-1690 had a higher chlorophyll/carotenoid ratio than CC-5325, suggesting more carotenoids in CC-5325 than CC-1690 (Figure 3f).

To evaluate photosynthetic performance, we imaged room temperature chlorophyll fluorescence in algal spots grown on TAP plates using FluorCam, a chlorophyll fluorescence imager (Photon System Instruments). Both strains had indistinguishable PSIl efficiency in dark and light on plates. However, CC-5325 had higher nonphotochemical quenching (NPQ) than CC-1690 (Figure 4a). NPQ is one of the most important photoprotective pathways in photosynthetic organisms, helps dissipate excess light energy, and protects photosynthesis (Dietz, 2015; Müller et al., 2001). To investigate photosynthetic parameters further, we used liquid algal cultures for detailed photosynthetic measurements. We performed $77 \mathrm{~K}$ chlorophyll fluorescence to check the relative antenna size of PSII and PSI (Lamb et al., 2018). CC-5325 had smaller PSII antenna size than CC-1690 (Figure 4b, c). By using a custom-designed kinetic spectrophotometer/fluorometer, we showed that CC-5325 had higher PSIl maximum efficiency in dark-adapted cells but lower PSIl operating efficiency under $400 \mu \mathrm{mol}$ photons $\mathrm{m}^{-2} \mathrm{~s}^{-1}$ light than $\mathrm{CC}-1690$ (Figure 4d). In response to the same light intensities, both strains had little difference in $Q_{A}$ redox status, except for $200 \mu \mathrm{mol}$ photons $\mathrm{m}^{-2} \mathrm{~s}^{-1}$ light (Figure 4e). By using the PSII\% (relative PSII antenna size or percentage of light distributed to PSII) estimated from our $77 \mathrm{~K}$ chlorophyll fluorescence data and PSII efficiency measured by room temperature chlorophyll fluorescence, we quantified linear electron flow (LEF) in response to light in these two strains (Figure 4f). CC-1690 had higher LEF than CC-5325 only at $400 \mu$ mol photons $\mathrm{m}^{-2} \mathrm{~s}^{-1}$ light. However, CC-5325 had much higher NPQ than CC-1690 under all three light intensities tested (Figure 4g). Additionally, by using a Hansatech Chlorolab 2 Clark-type oxygen electrode, we found 
CC-1690 had higher gross $\mathrm{O}_{2}$ evolution rates than $\mathrm{CC}-5325$ in response to the same light intensities while both had no differences in respiration rates (Figure 4h, i). Our results suggested that CC-5325 had lower photosynthetic efficiency than CC-1690.

We harvested algal cultures of CC-1690 and CC-5325 from PBRs, spotted them on agar plates with either TAP (with acetate, the supplied carbon source) or TP (Tris-phosphate medium, without acetate) medium, and grew them under different light and temperature conditions in incubators (Figure 5). CC-5325 grew better than CC-1690 in dark with acetate (Figure 5a). CC-1690 could grow in dark but appeared to have retarded growth as compared to $\mathrm{CC}-5325$. At $25^{\circ} \mathrm{C}$ and $35^{\circ} \mathrm{C}$ under $150 \mu \mathrm{mol}$ photons $\mathrm{m}^{-2} \mathrm{~s}^{-1}$ light in incubators, CC-1690 and CC-5325 had indistinguishable growth (Figure 5b-e, g). To evaluate the thermotolerance of these two strains under well-controlled temperature conditions in liquid cultures, we exposed the algal cultures to $43^{\circ} \mathrm{C}$ for $2 \mathrm{~h}$ in PBRs, then spotted the cells on agar plates to measure viability. CC- 5325 barely survived the heat of $43^{\circ} \mathrm{C}$; while CC- 1690 could survive $43^{\circ} \mathrm{C}$ heat better (Figure $5 \mathrm{f}$ ). Our results showed that both strains grew well photoautotropically and mixotrophically, but CC-5325 grew better under heterotrophic conditions while CC-1690 had higher thermotolerance than CC-5325.

Thermotolerance has been linked to cell wall properties (Xu et al., 2014; Gall et al., 2015), although it is unclear how cell walls affect thermotolerance. Because CC-5325 is a progeny from a cross between $4 \mathrm{~A}^{-}$(cell wall intact) and $\mathrm{D} 66^{+}$(cell wall deficient), CC-5325 is often thought to be cell wall deficient. We evaluated the cell walls of CC-1690 and CC5325 based on freezing tolerance, a detergent assay, and cell wall imaging (Figure 6-8). Cell-wall deficient strains are thought to recover better from liquid nitrogen freezing than cell-wall intact strains (Harris et al., 2009). Both CC-1690 and CC-5325 recovered equally well from liquid nitrogen freezing (Figure 6). Next, we used a detergent assay to evaluate the integrity of the cell wall. Triton X-100 is a detergent to disrupt lipid-based membranes and cause cells without an intact cell wall to lyse. Strains without intact cell wall or reduced cell wall integrity will have more damaged cells in the presence of Triton X-100, thus releasing more chlorophyll into the supernatant, which could be quantified using absorbance at $435 \mathrm{~nm}$. We included the well-studied cell-wall-deficient line cw15 as a control for this assay (Davies and Plaskitt, 1971; Hyams and Davies, 1972). Without Triton X-100, there was little chlorophyll released in all three lines (Figure 7a). With Triton $X-100$, all three lines had increased chlorophyll release, but CC-5325 had the least chlorophyll release while cw15 had the most, demonstrating the effectiveness of our assay. By using a Coulter Counter, we quantified the number of intact cells with and without Triton X-100 (Figure 7b). While Triton X-100 did not affect CC-1690 or CC-5325, it damaged nearly all cells of $c w 15$. Our freezing and detergent assays showed that CC1690 and CC-5325 had comparable cell wall integrity.

To directly visualize and quantify the cell wall, we used the lectin Concanavaline $A$ as a cell wall stain and Syto $13^{\mathrm{TM}}$ Green Fluorescent Nucleic Acid to label the nucleus, then imaged the cells using a ZEISS Elyra 7 super-resolution microscope (Figure 8). Our results showed that $\mathrm{CC}-1690$ and $\mathrm{CC}-5325$ had continuous and intact cell walls, while cw15 has discontinuous and broken cell walls, as expected for a cell-wall deficient mutant (Figure 8a-f). We calculated the total cell wall fluorescence intensity along each cell and 
normalized it to the cell perimeter length. The mean cell wall fluorescence intensity of CC5325 was $84 \%$ of that in CC-1690, while that in cw 15 was $17 \%$ relative to CC-1690 (Figure $8 \mathrm{~g}$ ). Based on our results of freezing recovery, detergent assays, and cell wall imaging, we conclude that CC-5325 is not that cell-wall deficient as previously described, instead it has intact cell wall with comparable integrity as that in CC-1690, but possibly thinner cell wall than that of CC-1690.

Lastly, we investigated the circadian rhythm of phototaxis in CC-1690 and CC-5325 because both phototaxis and circadian rhythm are important for photosynthesis, thermotolerance, and cell growth (Matsuo and Ishiura, 2010; Schulze et al., 2010; Dodd et al., 2015; Blair et al., 2019). Phototaxis was determined in day/night synchronized cultures using either "constant darkness" or "constant light" free-running conditions (Figure 9). Under constant dark conditions (Figure 9a-d), the darkness was interrupted every hour by a narrow, dim light beam directed through the culture for 15 min to allow for phototaxis measurements. In constant light conditions (Figure 9e-h), the white background light was turned off every hour for the 15 min of phototaxis measurement via the narrow, dim light beam. CC-1690 showed a robust circadian rhythm of phototaxis during either constant darkness or constant light. The period of the rhythm for CC-1690 was $27.65 \pm 0.13 \mathrm{~h}$ in constant darkness $(n=22$, mean \pm se) and $23.61 \pm 0.16 \mathrm{~h}$ in constant light $(n=12)$. However, in CC-5325 a sustained circadian rhythm of phototaxis could neither be detected in constant darkness nor in constant light. This inability was not simply due to an inability of the strain to undergo phototaxis (Figure $9 b$ and $f$ ). When monitoring the phototaxis of CC-5325, there seemed to be the start of a rhythm in nearly all cultures tested in constant light and in most of the cultures tested in constant darkness but only for the first 0.5 to 1.5 days (Figure $9 \mathrm{~b}$ and f). The lack of a sustained circadian rhythm of phototaxis in CC-5325 was true for cultures with different cell densities (from $0.5 \times 10^{6}$ to $1.6 \times 10^{6}$ cells $\mathrm{mL}^{-1}$ ). Our results clearly demonstrated that CC-1690 could maintain a sustained circadian rhythm of phototaxis but CC-5325 could not.

\section{Discussion}

We characterized and compared phenotypic differences between CC-1690 and CC-5325 by focusing on characteristics that are important for algal growth, including cell size, growth in liquid and on agar plates, photosynthesis, thermotolerance, cell wall integrity, and circadian rhythm of phototaxis. These two frequently used background strains displayed notable differences in these characteristics (Table 1).

Both strains grew well in liquid medium and on agar plates under normal conditions (Figure 2, 5). CC-5325 grew more robustly in dark with acetate than CC-1690 (Figure 5a), making it a promising background strain for mutants deficient in photosynthesis, which are often maintained in dark conditions with supplied carbon source. The reduced photosynthetic efficiency in CC-5325 may be related to smaller PSIl antenna size and/or increased NPQ as compared to CC-1690 (Figure 4c, g, h). The NPQ differences in these two strains may be relative, since NPQ from different strains may not be compared directly (Maxwell and Johnson, 2000; Baker et al., 2007). The increased NPQ in CC-5325 may be related to the reduced chlorophyll/carotenoid ratio (more carotenoids) (Figure $3 f$ ). Carotenoids have reported roles in photoprotection and one of the carotenoid pigments, 
zeaxanthin, has major roles in NPQ formation (Baroli et al., 2004; Erickson et al., 2015). The bigger PSI peak in CC-5325 suggested its preference for state 2 and reduced PSII antenna size as compared to CC-1690 (Lamb et al., 2018). Future investigation of genes/pathways related to state transition and NPQ may help explain these differences. CC-5325 has lower oxygen evolution rates than CC-1690 only under light intensity equal to or greater $200 \mu \mathrm{mol}$ photons $\mathrm{m}^{-2} \mathrm{~s}^{-1}$ light (Figure $4 \mathrm{~d}$ ), which may explain the comparable growth rates of these two strains in PBRs under $100 \mu \mathrm{mol}$ photons $\mathrm{m}^{-2} \mathrm{~s}^{-1}$ light (Figure 2). Although CC-5325 had lower photosynthetic efficiency than CC-1690, it does not compromise its suitability as a background strain to screen for mutants deficient in photosynthesis. Because photosynthetic efficiencies are relative, it is not necessary for a background strain to have the highest photosynthetic efficiency to study photosynthesis mutants; normal photosynthesis would be adequate. Previous research showed that CC5325 has a functional carbon concentrating mechanism (CCM) and several mutants deficient in CCM have been identified by using CC-5325 as a background strain (Mackinder et al., 2016; Itakura et al., 2019; Meyer et al., 2020). Mutants deficient in photosynthetic light reactions were also identified by using CLiP mutants on the background of CC-5325 (Chaux et al., 2017). Additionally, a genome-wide mutant screen has been performed to identify genes required for photosynthesis using the CLiP mutant library (Li et al., 2019). Based on our results and published literature, we believe CC-5325 is a suitable background to study photosynthesis in Chlamydomonas.

CC-5325 has been frequently referred as a cell-wall deficient line as cw15 (Li et al., 2016; Mukherjee et al., 2019). Our results from freezing and detergent assays showed that the cell wall integrity in CC-5325 was comparable to that in CC-1690 (Figure 6 and 7). Cell wall imaging and quantification showed that CC-5325 had an intact cell wall, albeit possibly thinner or reduced cell wall than that in CC-1690 (Figure 8). The vegetative cell wall of Chlamydomonas is mainly comprised of proteins (Lee et al., 2007; Cronmiller et al., 2019). It is possible that these two strains have different quantity of cell wall proteins. There are three classifications of cell-wall-deficient mutants: (A) normal quality of cell walls that are unattached to the plasma membrane; (B) normal quality of cell walls that are attached to the plasma membrane; (C) minimal amount of cell walls (Davies and Plaskitt, 1971). The well-studied cell-wall-deficient mutant, cw15, belongs to classification C (Davies and Plaskitt, 1971; Cronmiller et al., 2019). Our results showed that CC-5325 was clearly not a C-type cell-wall mutant. Chlamydomonas cell walls protect cells from environmental stresses (Cronmiller et al., 2019), but the underlying mechanisms are unclear. Further investigation is needed to investigate if the reduced cell wall in CC-5325 contributes to some of its increased heat sensitivity in comparison to CC-1690 (Figure 5). Nevertheless, the cell wall integrity in CC-5325 is clearly much better than previous thought and its increased heat sensitivity as compared to CC-1690 does not affect its use for studying heat responses. The CLiP mutant library has been used to screen for heat sensitive mutants (Vilarrasa-Blasi et al., 2020). It may not be necessary to cross CLiP mutants on the background of CC-5325 to other cell-wall intact strains. Additionally, for research related to heat stress, it may generate conflicting results if the heat-sensitive CLiP mutants were crossed to other non-isogeneic lines (e.g., CC-1690) because different background strains may have different heat sensitivity, as demonstrated in our research. If crossing is needed, a possibly better option would be to cross CLiP mutants 
to the isogenic strain of CC-5325, which is CC-5155 $\left(\mathrm{mt}^{+}\right)$, generated by backcrossing a $\mathrm{mt}^{+}$progeny of CC-5325 (mt) and CC-125 (mt') to CC-5325 five times (Li et al., 2016).

The most surprising result may be the lack of a sustained circadian rhythm of phototaxis in CC-5325, although the strain can perform phototaxis (Figure 9). Our results clearly showed a sustained circadian rhythm of phototaxis in CC-1690, but CC-5325 only showed an attempt of a rhythm limited to the first day or so. This lack of a rhythm in CC-5325 was independent of whether constant light or constant darkness was present during the freerunning condition. A number of different circadian rhythms have been studied in Chlamydomonas (Matsuo and Ishiura, 2010; Schulze et al., 2010), including phototaxis, chemotaxis, cell division, UV sensitivities, and others. How well Chlamydomonas can maintain these rhythms under various environmental conditions is less known. From our data, we cannot distinguish whether the lack of a sustained rhythm in CC-5325 is due to differences in its circadian clock compared to CC-1690 and therefore affecting also other circadian rhythms or whether it is specifically due to differences in how the circadian clock regulates phototaxis. If the first possibility is true, the reduced photosynthetic efficiency and thermotolerance observed in CC-5325 may be related to its deficiency in maintaining circadian rhythms, as normal circadian rhythms are important for photosynthetic organisms to optimize photosynthesis and acclimate to stressful environments (Dodd et al., 2015; García-Plazaola et al., 2017; Blair et al., 2019; Morales and Kaiser, 2020). In CC-1690, constant darkness or light affected the period of the rhythm, with a longer period in constant darkness $(27.65 \mathrm{~h})$ than constant light $(23.61 \mathrm{~h})$. Differences in period length under different constant conditions have been observed in many organisms. For example, it was recently reported that the duckweed, Lemna gibba, showed an average period under conditions of constant darkness that was about 7 hours longer than it was in constant light (Muranaka and Oyama, 2016). Transcriptome analysis in cultures under synchronizing versus free-running conditions may provide some insights about the mechanisms of the maintenance of circadian rhythms and about the basis for the observed differences between CC-1690 and CC-5325. Future work to investigate the underlying mechanisms by RNA-Seq or quantitative trait locus (QTL) mapping using CC1690 and CC-5325 may help elucidate the regulation of circadian rhythms in green algae and possibly other photosynthetic organisms.

QTL mapping has been used frequently to identify causative genes related to a phenotype in land plants (Xu et al., 2017; Camargo et al., 2018; Wu et al., 2018; Wang et al., 2018). Such analysis is much less developed in Chlamydomonas. However, Chlamydomonas has several advantages for QTL mapping as compared to land plants, e.g., high mating efficiency and easy mating procedure (Jiang and Stern, 2009), faster growth on plates or in liquid, low cost in whole genome sequencing (Dutcher et al., 2012; Wakao et al., 2021), and abundant RNA-Seq datasets (Salomé and Merchant, 2021). One round of mating in Chlamydomonas only takes about 2-3 weeks, from the mating process to identifiable progenies. Due to its unicellular nature, high throughput phenotyping tools could be applied efficiently to characterize progenies of Chlamydomonas, e.g., whole plate chlorophyll fluorescence imaging (Holub et al., 2007; Massoz et al., 2017; Rühle et al., 2018), growth quantification on plates using ImageJ (Zhang et al., 2021), and circadian rhythm monitoring using an automated phototaxis machine (Gaskill et al., 2010). The 
Chlamydomonas CLiP mutant library allows for both forward and reserve genetic screens and candidate genes identified by QTL in Chlamydomonas can be validated using available mutants in the CLiP mutant library (Li et al., 2016). If mutants deficient in some specific genes are unavailable in the CLiP mutant library or other mutant collections at the Chlamydomonas Resource Center, mutants disrupted in genes of interest could be generated by CRISPR-Cas 9 approaches with high efficiency (Greiner et al., 2017; Dhokane et al., 2020; Picariello et al., 2020). Comparison between genome sequences of CC-1690 and CC-5325 showed that these two strains had 117059 small variants and 355 high impact small variants (Li et al., 2016), providing potential candidates for phenotyping differences. Recently, research has been conducted in Chlamydomonas to phenotype and select progenies from a cross between two Chlamydomonas parental strains under different environmental conditions and revealed possible selection-enriched genomic loci for improved stress adaptation and photosynthetic efficiency (Lucker et al., 2021), paving the way for QTL mapping in Chlamydomonas.

\section{Conclusions}

We presented several distinct phenotypes between two commonly used laboratory background Chlamydomonas strains: CC-1690 (21gr) and CC-5325 (CLiP library background). Although CC-5325 has lower photosynthetic efficiency and thermotolerance than CC-1690, it does not compromise the use of CC-5325 and the CLiP mutant library to study and screen for mutants deficient in photosynthesis or heat responses. Our results showed CC-5325 had an intact cell wall with comparable integrity as that of CC-1690, which will help reduce researchers' concerns or confusion about its cell wall deficiency. The lack of a sustained circadian rhythm of phototaxis in CC-5325 does limit the use of the CLiP library to screen for mutants deficient in circadian rhythms of phototaxis. Finally, the rich genomic and genetic resources in Chlamydomonas will enable efficient identification of responsible genes for phenotypes related to cell size, photosynthesis, thermotolerance, and circadian rhythms in the near future.

\section{Materials and Methods \\ Strains and culture conditions}

Chlamydomonas wildtype strain CC-1690 (also called $21 \mathrm{gr} \mathrm{mt}^{+}$) and CC-5325 (also called CMJ030, identical to CC-4533, mt', CLiP library background) were ordered from the Chlamydomonas resource center. Algal cultures of these two strains were maintained in photobioreactors (PBRs) as described before (Zhang et al., 2021). The normal growth condition in PBRs was: $25^{\circ} \mathrm{C}$, Tris-acetate-phosphate (TAP) medium, constant $100 \mu \mathrm{mol}$ photons $\mathrm{m}^{-2} \mathrm{~s}^{-1}$ light (50\% red: $50 \%$ blue), constant bubbling with filtered air $\left(0.04 \% \mathrm{CO}_{2}\right)$, and turbidostatic control by monitoring $\mathrm{OD}_{680}$ to supply fresh medium frequently and maintain cell density around $2 \times 10^{6}$ cells $\mathrm{mL}^{-1}$. Under the normal growth condition at $25^{\circ} \mathrm{C}$, $\mathrm{OD}_{680}$ is linearly proportional to both chlorophyll content and cell density. Fresh medium was added to the culture automatically by a peristaltic pump when the $\mathrm{OD}_{680}$ reached the defined maximum value to dilute the culture; the pump was stopped when the $\mathrm{OD}_{680}$ dropped to the defined minimum value. Algal cultures then grew up at approximately exponential rate to the defined maximum $\mathrm{OD}_{680}$ value before the next dilution cycle. Our $\mathrm{OD}_{680}$ range was sufficiently small that we expected minimal nutrient limitation during our experiment. Thus, the turbidostatic mode precisely controlled the growth condition. We 
calculated the doubling time or relative growth rates based on the exponential growth phase when the peristaltic pump was off. The doubling time and relative growth rates we referred to were based on the increase of $\mathrm{OD}_{680}$ or the total chlorophyll per $\mathrm{mL}$ culture. The growth rates measured by $\mathrm{OD}_{680}$ were consistent with medium consumption rates and cell number increase quantified by a cell counter. For the $43^{\circ} \mathrm{C}$ heat treatment in PBRs, the PBR temperature was gradually increased from $25^{\circ} \mathrm{C}$ to $43^{\circ} \mathrm{C}$ within $30 \mathrm{~min}$, and then the PBR temperature was maintained at $43^{\circ} \mathrm{C}$ for $2 \mathrm{~h}$. By the end of $2-\mathrm{h}$ heating at $43^{\circ} \mathrm{C}$, algal cultures were harvested for spotting test to evaluate viability.

\section{Algal spotting test}

Algal spotting test was performed as described before with minor modifications (Zhang et al., 2021). CC-1690 and CC-5325 cultures harvested from PBRs were diluted to $1 \times 10^{5}$ cells $\mathrm{mL}^{-1}$ or $0.2 \times 10^{5}$ cells $\mathrm{mL}^{-1}$ (1:20 or $1: 100$ dilution) and $10 \mu \mathrm{L}$ aliquots of the diluted cultures (about 1000 or 200 cells) were spotted on $1.5 \%$ TAP agar plates and grown in temperature-controlled incubators under the indicated conditions. For conditions with light, $150 \mu \mathrm{mol}$ photons $\mathrm{m}^{-2} \mathrm{~s}^{-1}$ light light was provided by white LED lights with indicated intensity. After 44-h growth under light in incubators, algal spots were imaged by a dissecting Leica microscope. The whole plates with algal spots were imaged again using a regular camera after 3-day-growth for visual representations. Due to the slow growth in darkness, the algal spots and the whole plates were images after 5-day and 10-day, respectively.

\section{Pigment measurements}

Pigments were quantified as described before (Zhang et al., 2021). Three biological replicates of $1 \mathrm{~mL}$ of PBR cultures (around $2 \times 10^{6}$ cells mL-1) grown under normal condition of $25^{\circ} \mathrm{C}$ were harvested, mixed with $2.5 \mu \mathrm{L}$ of $2 \%$ Tween20 (Sigma, P9416-100ML) to help cell pelleting, centrifuged at $18,407 \mathrm{~g}$ at $4^{\circ} \mathrm{C}$ to remove supernatant. Cell pellets were resuspended in $1 \mathrm{~mL}$ of HPLC grade methanol (100\%, Sigma, 34860-4L-R), vortexed for $1 \mathrm{~min}$, incubated in the dark for $5 \mathrm{~min}$ at $4^{\circ} \mathrm{C}$, and centrifuged at $15,000 \mathrm{~g}$ at $4^{\circ} \mathrm{C}$ for $5 \mathrm{~min}$. Top supernatant containing pigments was analyzed at 470,652, $665 \mathrm{~nm}$ in a spectrophotometer (IMPLEN Nonophotometer P300) for carotenoids and chlorophyll a/b concentrations in $\mu \mathrm{g} \mathrm{mL} \mathrm{m}^{-1}$ using the following equations: $\mathrm{Chl} a+\mathrm{Chl} \mathrm{b}=22.12^{*} \mathrm{~A}_{652}+$ $2.71^{\star} A_{665}, \mathrm{Chl} a=16.29^{*} A_{665}-8.54^{*} A_{652}$, and $\mathrm{Chl} b=30.66{ }^{*} A_{652}-13.58^{*} A_{665}$ (Porra et al., 1989), and carotenoids $=\left(100{ }^{\star} \mathrm{A} 470-2.86^{\star} \mathrm{Chl} \mathrm{a}-129.2^{\star} \mathrm{Chl} b\right) / 221$ (Wellburn, 1994).

\section{Photosynthetic measurements}

CC-1690 and CC-5325 cultures grown at $25^{\circ} \mathrm{C}$ in PBRs as mentioned above were used for all photosynthetic measurements. Algal cultures were spotted on TAP plates and grown under $150 \mu \mathrm{mol}$ photons $\mathrm{m}^{-2} \mathrm{~s}^{-1}$ light at $25^{\circ} \mathrm{C}$ in incubators for 4-day. Algal plates were dark-adapted for $20 \mathrm{~min}$ before chlorophyll fluorescence imaging at room temperature using FluorCam (Photo System Instruments). Photosynthetic measurements in liquid algal cultures were performed as described before (Zhang et al., 2021). $77 \mathrm{~K}$ chlorophyll fluorescence measurement were performed using an Ocean Optics spectrometer (cat. No. OCEAN-HDX-XR) and $430 \mathrm{~nm}$ excitation provided by light emitting diodes (LEDs). Spectral data were normalized to the PSII spectral maximum value at 686 $\mathrm{nm}$ and relative percentage of light distributed to PSII (or relative PSII antenna size, PSII\%) 
was calculated using this formula: PSII\%= normalized PSII peak / (normalized PSII peak + normalized PSI peak at $714 \mathrm{~nm}$ ). Normalized PSII peak equals one. Room temperature chlorophyll fluorescence in liquid algal cultures were performed using a multi-wavelength kinetic spectrophotometer or fluorometer (measuring beam with $505 \mathrm{~nm}$ peak emission, measuring pulses of $100 \mu \mathrm{s}$ duration) (Zhang et al., 2021). Aliquots of $2.5 \mathrm{~mL}$ algal cultures (around $12 \mu \mathrm{g}$ chlorophyll) were sampled from PBRs, supplemented with $25 \mu \mathrm{L}$ of fresh $0.5 \mathrm{M} \mathrm{NaHCO}_{3}$ in a fluorometry cuvette (C0918, Sigma-Aldrich) with constant stirring, and dark adapted with a 10-min exposure to far-red light (peak emission of 730 $\mathrm{nm}$ at $\sim 35 \mu \mathrm{mol}$ photons $\mathrm{m}^{-2} \mathrm{~s}^{-1}$ ) before chlorophyll fluorescence measurement in dark, and subsequent actinic light phases of 100, 200, $400 \mu \mathrm{mol}$ photons $\mathrm{m}^{-2} \mathrm{~s}^{-1}$ light. The actinic light was provided by LED lights with maximal emission at $620 \mathrm{~nm}$. Each light phase was about 7.5 min long. A saturating flash was applied at the end of each phase to get maximum chlorophyll fluorescence ( $F_{m}$ in dark or $F_{m}$ ' in light). Photosynthetic parameters were calculated as described (Baker et al., 2007). PSII efficiency (ФPSII) was calculated as $1-F_{0} / F_{m}$ and $1-F^{\prime} / F_{m}$ for dark-adapted and light-adapted algal cells, respectively. $F_{o}$ and $F_{m}$ are minimal and maximal chlorophyll fluorescence in darkadapted algal cells. $F^{\prime}$ and $F_{m}$ ' are steady state and maximal chlorophyll fluorescence in light-adapted algal cells. $Q_{A}$ redox status was calculated as $1-q_{L}=1-\left(F_{q}{ }^{\prime} / F_{v}{ }^{\prime}\right) \times\left(F_{O}{ }^{\prime} / F^{\prime}\right)=1-$ $\left[\left(F_{m}{ }^{\prime}-F^{\prime}\right) /\left(F_{m}{ }^{\prime}-F_{o}{ }^{\prime}\right)\right] x\left(F_{o}^{\prime} / F^{\prime}\right) . \quad q_{L}$ is the fraction of open PSII centres and $F_{q}{ }^{\prime}$ is the photochemical quenching of fluorescence (Baker et al., 2007). Linear electron flow (LEF) was calculated using the formula: LEF = (actinic light) $\times\left(\right.$ Qabs $\left._{\mathrm{fs}}\right) \times(\mathrm{PSI} \%) \times($ $)$ PSII). $Q a b S_{\mathrm{fs}}$ is fraction of absorbed light, assuming 0.8. PSII\% was calculated from $77 \mathrm{~K}$ chlorophyll fluorescence as mentioned above. Non-photochemical quenching, NPQ, was calculated as $\left(F_{m}-F_{m}{ }^{\prime}\right) / F_{m}$ '. Oxygen evolution was measured using the Hansatech Chlorolab 2 based on a Clark-type oxygen electrode at room temperature as described (Zhang et al., 2021). Two-mL of cells (around $10 \mu \mathrm{g}$ chlorophyll) supplemented with 20 $\mu \mathrm{L}$ of $0.5 \mathrm{M} \mathrm{NaHCO}_{3}$ were incubated in the dark for 10 min with stirring before the light phases of 100, 200, $400 \mu \mathrm{mol}$ photons $\mathrm{m}^{-2} \mathrm{~s}^{-1}$ light. Each light lasted 5 min followed by 2 min dark. The rates of oxygen evolution and respiration were measured at the end of each light and dark phase, respectively.

\section{Algal cryogenic freezing and thawing}

CC-1690 and CC-5325 cultures around a cell density of $2 \times 10^{6}$ cells $\mathrm{mL}^{-1}$ were harvested from PBRs grown at $25^{\circ} \mathrm{C}$ and frozen in $10 \%$ cryoprotective agent (CPA, 1:10 volume ratio of $100 \%$ methanol and fresh TAP medium). Algal cultures of $450 \mu \mathrm{L}$ was added to $450 \mu \mathrm{L}$ of $10 \%$ CPA (final CPA concentration was $5 \%$ ) in cryo-tubes, mixed gently, transferred to a CoolCell foam freezer container, incubated in a $-80^{\circ} \mathrm{C}$ freezer for $4 \mathrm{~h}$, and finally stored in a liquid nitrogen freezer. During the thawing process, cryo-tubes with algal samples were thawed in a $37^{\circ} \mathrm{C}$ water bath for $5 \mathrm{~min}$ and centrifuged at $1000 \mathrm{~g}$ for $5 \mathrm{~min}$ at room temperature to remove the supernatant. Fresh TAP medium of $900 \mu \mathrm{L}$ was added to resuspend cell pellets, followed by dark storage of the cryo-tubes without agitation at room temperature overnight. The next day, the cryo-tubes were centrifuged again at 1000 $\mathrm{g}$ for $5 \mathrm{~min}$ at room temperature to remove the supernatant. Cell pellets were resuspended with $200 \mu \mathrm{L}$ of fresh TAP medium and $10 \mu \mathrm{L}$ of the resuspended algal cultures were used for the spotting test to evaluate viability as mentioned above. 


\section{Detergent assay for cell wall integrity}

CC-1690 and CC-5325 cultures around a cell density of $2 \times 10^{6}$ cells $\mathrm{mL}^{-1}$ were harvested from PBRs grown at $25^{\circ} \mathrm{C}$ as mentioned above. A cell-wall deficient strain, cw15 (Davies and Plaskitt, 1971), was received from the Umen laboratory and used as a control. cw15 could not grow well in PBRs probably because its cell wall deficiency made it sensitive to the constant air bubbling in PBRs. So shaker cultures of cw15 around the similar cell density were used for the detergent assay. Growth condition of $c w 15$ on the shaker was $25^{\circ} \mathrm{C}$, around $100 \mu \mathrm{mol}$ photons $\mathrm{m}^{-2} \mathrm{~s}^{-1}$ light, and in TAP medium. One-mL algal cultures were used for chlorophyll quantification (Porra et al., 1989) and another 1-mL cultures (with $0.05 \%$ Triton X-100 or with TAP medium) were immediately vortexed vigorously for $30 \mathrm{~s}$ then incubated in dark for $10 \mathrm{~min}$. Then, $500 \mu \mathrm{L}$ of each sample was withdrawn and centrifuged at $13,000 \times \mathrm{g}$ to remove cell debris. The absorbance of the supernatant was measured at $435 \mathrm{~nm}$ and normalized to chlorophyll contents. The number of intact cells were measured using a Coulter Counter (Multisizer 3, Beckman Counter, Brea, CA).

\section{Cell wall staining and quantification}

Ten $\mathrm{mL}$ cultures of CC-1690, CC-5325 and cw15 cells as mentioned above were collected and concentrated to $2 \times 10^{7}$ cells $\mathrm{mL}^{-1}$ by centrifugation at $1500 \mathrm{~g}$ for $5 \mathrm{~min}$ at room temperature. Cells were stained with Concanavaline A (ConA, Alexa Fluor ${ }^{\circledR} 594$ conjugate) (100 $\mathrm{g} \mathrm{mL} \mathrm{m}^{-1}$, ThermoFisher Scientific) (Bensalem et al., 2018) and Syto 13 Green Fluorescent Nucleic Acid Stain ( $5 \mu \mathrm{M} \mathrm{mL}^{-1}$, ThermoFisher Scientific) for $30 \mathrm{~min}$ at room temperature. Stained cells were washed first and then fixed in $4 \%$ paraformaldehyde (EM Science, Hatfield, PA, USA) and followed by 1X rinse in TAP medium. Fluorescence images were acquired using a 40x C-Aprochromat objective lens (numerical aperture 1.2) in apotome mode with a ZEISS Elyra 7 super-resolution microscope (ZEISS, Oberkochen, Germany). The $488 \mathrm{~nm}$ and $561 \mathrm{~nm}$ laser lines with BP 420-480 + 495-550 and BP 570-620 + LP 655 emission filters were used for Syto 13 and ConA, respectively in fast frame sequential mode at $50 \mathrm{~ms}$ exposure using dual pco.edge 4.2 sCMOS detectors (PCO AG, Kelheim, Germany). All two-dimensional (2D) images (with 5 phases) were acquired at $49 \mathrm{~nm} x-y$ pixel resolution and reconstructed using the $\mathrm{SIM}^{2}$ module and 2D+ processing with standard live sharpness in ZEN Black 3.0 SR FP2 software. For each strain, 100 cells were quantified by free hand drawing a line intensity profile along the cell wall. The fluorescence intensity of each cell wall periphery was normalized by its perimeter length.

\section{Circadian rhythm of phototaxis}

CC-1690 and CC-5325 were grown in 125-mL Erlenmeyer flasks containing 50-mL photoautotrophic Tris-phosphate (TP) minimum medium without acetate. Cultures were grown on a shaker at 17 to $19^{\circ} \mathrm{C}$ under synchronizing $12 \mathrm{~h}$ light/12 $\mathrm{h}$ dark cycles. The light intensity during the light phase was about $20 \mu \mathrm{mol}$ photons $\mathrm{m}^{-2} \mathrm{~s}^{-1}$. When cultures reached cell concentrations between $3.5 \times 10^{5}$ and $2.3 \times 10^{6}$ cells mL $\mathrm{m}^{-1}$, culture samples were placed into small Petri dishes and their phototaxis was monitored at $20^{\circ} \mathrm{C}$ as described (Gaskill et al., 2010) with the following modifications. A box around the phototaxis machine with a heating element and ventilators allowed the external temperature around the machine to be kept at a constant but slightly elevated temperature of $24^{\circ} \mathrm{C}$ compared to the machine. Additionally, temperature recorders 
(Tempo Disc, BlueMaestro) that fit into the Petri dish slots allowed for a more precise monitoring of the temperature the culture samples were exposed to. An algorithm as described before was used to analyze the phototaxis data for their periods (Gaskill et al., 2010). Three independent experiments were conducted for each of the constant darkness and constant light conditions with 1 or 2 different cultures per strain per experiment and 3 to 4 replicate samples per culture.

\section{Statistical analysis}

A two-tailed t-test with unequal variance was used for statistical analysis. $P>0.05$, not significant, or ns; * $0.01<\mathrm{P}<0.05 ;{ }^{* *}, 0.001<\mathrm{P}<0.01$; ${ }^{* *}, \mathrm{P}<0.001$.

\section{Author contributions}

R.Z. supervised the project. R.Z. wrote the manuscript with the help from S. J., N.Z., and K.J.C.. N.Z. performed freezing test and detergent assay. L.P. performed room temperature chlorophyll fluorescence measurements and $\mathrm{O}_{2}$ evolution in liquid algal cultures. H.N. initiated the project, performed FluorCam imaging, and $77 \mathrm{~K}$ chlorophyll fluorescence measurements. S. J. performed the experiments of circadian rhythm of phototaxis. M. X. maintained algal cultures in photobioreactors, performed spotting and thermotolerance tests. N.Z., H.N., M.X. quantified pigments. N.Z., A. K., K.J.C. performed cell wall imaging. R.Z. and M.X. polished most of the figures. R.Z., S. J., K.J.C., L.P., and H.N. helped revise the manuscript.

\section{Acknowledgements}

This research was supported by the start-up funding from the Donald Danforth Plant Science Center (DDPSC), the Department of Energy (DOE) Basic Energy Sciences (BES) Photosynthetic Systems (PS) grant (Award No. 0019464), and the DOE Biological \& Environmental Research (BER) grant (Award No. 0020400) to R.Z. We acknowledge imaging support from the Advanced Bioimaging Laboratory (RRID:SCR_018951) at the Danforth Plant Science Center and usage of the ZEISS Elyra 7 Super-Resolution Microscope acquired through an NSF Major Research Instrumentation grant (DBI2018962). We would like to thank Dr. Dmitri Nusinow, Erin Mattoon, and Cooper Hostetler for providing feedback for the manuscript. Dr. Dmitri Nusinow and Maria Sorkin are acknowledged for initial analysis of circadian rhythms in algal cells. We also want to thank Catherine Bailey for help with some of the pigment analysis.

\section{Data Availability Statement}

The data presented in this study are available in this article.

\section{Conflicts of Interest}

The authors declare no conflict of interest.

\section{Figure legends}

Figure 1. CC-5325 had larger cell volume than CC-1690. (a, b) Light microscopic images of Chlamydomonas cells. (c) Boxplot of mean cell volume determined using a Coulter Counter. $n=12$ biological replicates for each strain. Statistical analyses were 
performed using a two-tailed t-test assuming unequal variance by comparing with CC1690. ${ }^{* * *}, \mathrm{P}<0.001$.

Figure 2. CC-1690 and CC-5325 had comparable growth rates under mixotrophic conditions in photobioreactors. Chlamydomonas cells were grown in turbidostatically controlled photobioreactors (PBRs) in Tris-acetatephosphate (TAP) medium at $25^{\circ} \mathrm{C}$ with a light intensity of $100 \mu \mathrm{mol}$ photons $\mathrm{m}^{-2} \mathrm{~s}^{-1}$ and constantly bubbling of air. Doubling time (a) and relative growth rates (b, inverse of doubling time) were calculated based on the exponential increase of $\mathrm{OD}_{680}$, which is proportional to total chlorophyll content in unit of $\mu \mathrm{g}$ chlorophyll $\mathrm{mL}^{-1}$ and cell density at $25^{\circ} \mathrm{C}$. Mean $\pm \mathrm{SE}, \mathrm{n}=3$ biological replicates. Statistical analyses were performed using a two-tailed t-test assuming unequal variance by comparing the two strains; ns, not significant.

Figure 3. CC-5325 had more chlorophyll and carotenoids per cell than CC-1690, mainly due to the larger cell volume of CC-5325. Chlorophyll and carotenoids measured by absorbance change using a spectrophotometer. Mean $\pm \mathrm{SE}, \mathrm{n}=3$ biological replicates. Statistical analyses were performed using a two-tailed t-test assuming unequal variance by comparing with $\mathrm{CC}-1690$ : *, $\mathrm{P}<0.05$; ns, not significant.

Figure 4. CC-1690 had higher photosynthetic efficiency than CC-5325. (a) Chlorophyll fluorescence imaging of 4-day-old algal spots grown on TAP plates at $25^{\circ} \mathrm{C}$ under $150 \mu \mathrm{mol}$ photons $\mathrm{m}^{-2} \mathrm{~s}^{-1}$ white LED lights in incubators. Imaging was performed by using FluorCam (Photo System Instruments). QY-max, maximum PSIl efficiency in darkadapted plates. Under $780 \mu \mathrm{mol}$ photons $\mathrm{m}^{-2} \mathrm{~s}^{-1}$ light, $\mathrm{Q}_{\mathrm{Y}}$ and NPQ are PSIl operating efficiency and non-photochemical quenching (NPQ) in light adapted plates, respectively. Color bars represent values of $Q_{Y}$ and NPQ. (b-i) Algal cells grown in PBRs under the same condition as in Figure 2 were harvested for photosynthetic measurements. (b) 77 $\mathrm{K}$ chlorophyll fluorescence normalized to PSII peak at $686 \mathrm{~nm}$. (c) PSII\%, relative PSII antenna size, or light distributed to PSII, estimated from $77 \mathrm{~K}$ chlorophyll fluorescence data in (b). (d-g) Room temperature chlorophyll fluorescence measurements were performed in algal liquid cultures using a custom-designed spectrophotometer, see methods for details. (d) PSIl efficiency, the data at $0 \mu \mathrm{mol}$ photons $\mathrm{m}^{-2} \mathrm{~s}^{-1}$ light is the maximum PSII efficiency in dark and data from light phase is PSII operating efficiency in light-adapted cells. (e) $Q_{A}$ redox state, the redox state of chloroplastic quinone $A\left(Q_{A}\right)$, the primary electron acceptor downstream of PSII; the bigger number of $Q_{A}$ redox state means more reduced $Q_{A}$. (f) Linear electron flow. (g) Non-photochemical quenching, NPQ. (h, i) Gross $\mathrm{O}_{2}$ evolution rates and respiration rates, measured using a Hansatech Chlorolab 2 Clark-type oxygen electrode. Mean \pm SE, $n=3$ biological replicates. (c-i) All figures have error bars, but some error bars may be too small to be visible on the graph. Statistical analyses were performed using a two-tailed t-test assuming unequal variance by comparing with $\mathrm{CC}-1690$ under the same experimental conditions. ${ }^{*}, 0.01<\mathrm{P}<0.05$; ${ }^{*}$, $0.001<\mathrm{P}<0.01$; ${ }^{* * *}, \mathrm{P}<0.001$; ns, not significant. (d-i) The positions of asterisks match the corresponding light intensities.

Figure 5. CC-5325 grew better in dark with acetate but was more heat sensitive than CC-1690. (a-e) Algal cells grown in PBRs under the same condition as in Figure 2 were 
harvested, diluted, and spotted on agar plates, and grown under the indicated growth conditions in temperature-controlled incubators. Cultures with the same cell density were used for each spot. (f) Algal cells were heat-treated at $43^{\circ} \mathrm{C}$ for $2-\mathrm{h}$ in PBRs before spotting; cultures with equal volume and the same dilution were used for each spot. TAP, Tris-acetate-phosphate medium with acetate. TP, Tris-phosphate medium without acetate. The same dilution and growth duration were used for the two strains under the same condition. (a, f) Algal cultures with 1:20 dilution, about 1000 cells in $10 \mu \mathrm{L}$, were used for spotting. (b-e) Algal cultures with 1:100 dilution, about 200 cells in $10 \mu \mathrm{L}$, were used for spotting. Single algal spots were imaged using a dissect microscope after 5-day (a) or 44-h (b-f) of growth. Plate images (all 1: 20 dilution) were taken after 10-day (a) or 3-days (b-f) of growth using a regular camera. Images shown are representative of three biological replicates. (g) Normalized cell area. The 44-h spotting images were analyzed by ImageJ to get cell areas which were then normalized to the number of cells spotted. Statistical analyses were performed using a two-tailed t-test assuming unequal variance by comparing with CC-1690 under the same experimental conditions; ns, not significant. Such quantification was not performed for $(\mathbf{a}, \mathbf{f})$ because the cell areas for one of the strains were too small to do the quantification.

Figure 6. CC-1690 and CC-5325 recovered from liquid nitrogen freezing equally well. (a, b) Representative images of CC-1690 and CC-5325 after thawing from liquid nitrogen freezing. (c) Cell viability before and after freezing quantified by the No. of colonies on TAP plates. (d) Colony area on TAP plates for cells before and after freezing, normalized to the total number of cells spotted for each condition. The numbers of intact cells before and after freezing in liquid cultures were measured using a Coulter Counter and diluted cultures were spotted on TAP plates. TAP plates with algal spots were grown at $25^{\circ} \mathrm{C}$ under $150 \mu \mathrm{mol}$ photons $\mathrm{m}^{-2} \mathrm{~s}^{-1}$ white LED lights for 44-h before plate imaging. Colony numbers and areas were quantified using ImageJ. Cell viability was calculated by the No. of colonies on TAP plates divided by the No. of cells spotted. Mean $\pm S E, n=3$ biological replicates. Statistical analyses were performed using a two-tailed t-test assuming unequal variance by comparing the two strains under the same experimental conditions. No significant differences between these two strains under the same conditions, ns, not significant, $\mathrm{P}>0.05$.

Figure 7. CC-1690 and CC-5325 had comparable resistance to the detergent Triton $\mathbf{X}-100$. Detergent assay was performed to check cell wall integrity. Triton $X-100$ is a detergent to disrupt lipid-based membranes and cause cells without an intact cell wall to lyse. Algal samples with and without $0.05 \%$ Triton X-100 were vortexed vigorously. Strains without intact cell walls will have more broken cells in the presence of Triton X100 and thus more released chlorophyll than strains with intact cell walls. (a) Released chlorophyll from damaged cells were quantified using absorbance at $435 \mathrm{~nm}$. (b) The percentage of intact cells were quantified using a Coulter Counter. Mean \pm SE, $n=3$ biological replicates. Statistical analyses were performed using a two-tailed t-test assuming unequal variance by comparing with CC-1690 under the same experimental conditions $\left({ }^{*}, \mathrm{P}<0.05\right)$ or within the same strain in the presence or absence of Triton $\mathrm{X}$ 100 (\#, P<0.05; ns, not significant, $\mathrm{P}>0.05$ ). 
Figure 8. CC-5325 had intact cell wall which may be thinner than that in CC-1690. CC-1690, CC-5325 and cw15 cells were stained with Concanavalin A for cell wall imaging and Syto $13^{\mathrm{TM}}$ Green Fluorescent Nucleic Acid to label the nucleus. cw15, a cell-walldeficient line, was used as a control. (a-c) Representative images for cell wall stain (majenta color) and nuclear stain (green color) for three different strains. (d-f) Cell wall fluorescence quantification; the scale for cell wall fluorescence intensity is in the vertical direction, taller peaks represent greater fluorescence intensity. (a,d), (b, e), (c,f): data for CC-1690, CC-5325, and cw15, respectively. (g) Boxplot for cell wall fluorescence quantification. Total fluorescence intensity of each cell wall was normalized to the cell perimeter length. About 100 cells were quantified for each strain for fluorescence intensity. Statistical analyses were performed using a two-tailed t-test assuming unequal variance by comparing with $\mathrm{CC}-1690\left({ }^{*}, \mathrm{P}<0.05 ;{ }^{* * *}, \mathrm{P}<0.001\right)$ or between $\mathrm{CC}-5325$ and $c w 15$ (\#\#\#, P<0.001).

Figure 9: In constant darkness or constant light, CC-1690 maintained a sustained circadian rhythm of phototaxis but CC-5325 could not. All graphs on the left depict data for CC-1690 and those on the right for CC-5325. (a, b, e, f): Example graphs of the raw data as collected by the phototaxis machine. Each vertical line in the graph shows the light transmission measurements the machine collected at 1-minute intervals during the 15 minutes when a narrow, weak test light beam was directed through the culture sample and cells accumulated in the beam. This 15-minute test light beam was repeated every hour. During the 45 minutes that separated consecutive light beams, culture samples were exposed to constant darkness (a-d) or constant light $(\mathbf{e}-\mathbf{h})$. (c, $\mathbf{d}, \mathbf{g}, \mathbf{h})$ The raw data from the above graphs (blue line) were fed into an analysis algorithm leading to the best-fit sine wave the algorithm determined for the raw data (red line). Only a single data point of the raw data was used by the algorithm per 15-minute test light cycle, the transmission measured after 11 minutes into the light beam.

Table 1: Summary of phenotypic differences between CC-1690 and CC-5325.

\section{References}

Amiya, R. and Shapira, M. (2021). ZnJ6 Is a thylakoid membrane DnaJ-Like chaperone with oxidizing activity in Chlamydomonas reinhardtii. Int J Mol Sci 22: 1136.

Atteia, A. et al. (2009). A proteomic survey of Chlamydomonas reinhardtii mitochondria sheds new light on the metabolic plasticity of the organelle and on the nature of the alpha-proteobacterial mitochondrial ancestor. Mol Biol Evol 26: 1533-1548.

Baker, N.R., Harbinson, J., and Kramer, D.M. (2007). Determining the limitations and regulation of photosynthetic energy transduction in leaves. Plant, Cell \& Environment 30: 1107-1125.

Baroli, I., Gutman, B.L., Ledford, H.K., Shin, J.W., Chin, B.L., Havaux, M., and Niyogi, K.K. (2004). Photo-oxidative stress in a xanthophyll-deficient mutant of Chlamydomonas. J Biol Chem 279: 6337-6344. 
Bensalem, S., Lopes, F., Bodénès, P., Pareau, D., Français, O., and Le Pioufle, B. (2018). Structural changes of Chlamydomonas reinhardtii cells during lipid enrichment and after solvent exposure. Data Brief 17: 1283-1287.

Blaby, I.K., Blaby-Haas, C.E., Pérez-Pérez, M.E., Schmollinger, S., Fitz-Gibbon, S., Lemaire, S.D., and Merchant, S.S. (2015). Genome-wide analysis on Chlamydomonas reinhardtii reveals the impact of hydrogen peroxide on protein stress responses and overlap with other stress transcriptomes. Plant J 84: 974988.

Blaby-Haas, C.E., Castruita, M., Fitz-Gibbon, S.T., Kropat, J., and Merchant, S.S. (2016). Ni induces the CRR1-dependent regulon revealing overlap and distinction between hypoxia and $\mathrm{Cu}$ deficiency responses in Chlamydomonas reinhardtii. Metallomics 8: 679-691.

Blair, E.J., Bonnot, T., Hummel, M., Hay, E., Marzolino, J.M., Quijada, I.A., and Nagel, D.H. (2019). Contribution of time of day and the circadian clock to the heat stress responsive transcriptome in Arabidopsis. Sci Rep 9: 4814.

Camargo, A.V., Mackay, I., Mott, R., Han, J., Doonan, J.H., Askew, K., Corke, F., Williams, K., and Bentley, A.R. (2018). Functional mapping of quantitative trait loci (QTLs) associated with plant performance in a wheat MAGIC mapping population. Frontiers in Plant Science 9: 887.

Chaux, F., Burlacot, A., Mekhalfi, M., Auroy, P., Blangy, S., Richaud, P., and Peltier, G. (2017). Flavodiiron proteins promote fast and transient $\mathrm{O}_{2}$ photoreduction in Chlamydomonas. Plant Physiology 174: 1825-1836.

Cronmiller, E., Toor, D., Shao, N.C., Kariyawasam, T., Wang, M.H., and Lee, J.-H. (2019). Cell wall integrity signaling regulates cell wall-related gene expression in Chlamydomonas reinhardtii. Sci Rep 9: 12204.

Cross, F.R. and Umen, J.G. (2015). The Chlamydomonas cell cycle. Plant J 82: 370392.

Crozet, P. et al. (2018). Birth of a photosynthetic chassis: A MoClo toolkit enabling synthetic biology in the microalga Chlamydomonas reinhardtii. ACS Synth. Biol. 7: 2074-2086.

Davies, D.R. and Plaskitt, A. (1971). Genetical and structural analyses of cell-wall formation in Chlamydomonas reinhardi. Genetics Research 17: 33-43.

Dhokane, D., Bhadra, B., and Dasgupta, S. (2020). CRISPR based targeted genome editing of Chlamydomonas reinhardtii using programmed Cas9-gRNA ribonucleoprotein. Mol Biol Rep 47: 8747-8755.

Dietz, K.-J. (2015). Efficient high light acclimation involves rapid processes at multiple mechanistic levels. J Exp Bot 66: 2401-2414. 
Dodd, A.N., Belbin, F.E., Frank, A., and Webb, A.A.R. (2015). Interactions between circadian clocks and photosynthesis for the temporal and spatial coordination of metabolism. Frontiers in Plant Science 6: 245.

Dutcher, S.K., Li, L., Lin, H., Meyer, L., Giddings, T.H., Kwan, A.L., and Lewis, B.L. (2012). Whole-genome sequencing to identify mutants and polymorphisms in Chlamydomonas reinhardtii. G3 (Bethesda) 2: 15-22.

Emrich-Mills, T.Z., Yates, G., Barrett, J., Girr, P., Grouneva, I., Lau, C.S., Walker, C.E., Kwok, T.K., Davey, J.W., Johnson, M.P., and Mackinder, L.C.M. (2021). A recombineering pipeline to clone large and complex genes in Chlamydomonas. The Plant Cell 33: 1161-1181.

Erickson, E., Wakao, S., and Niyogi, K.K. (2015). Light stress and photoprotection in Chlamydomonas reinhardtii. Plant J 82: 449-465.

Flowers, J.M. et al. (2015). Whole-genome resequencing reveals extensive natural variation in the model green alga Chlamydomonas reinhardtii. The Plant Cell 27: 2353-2369.

Gall, H.L., Philippe, F., Domon, J.-M., Gillet, F., Pelloux, J., and Rayon, C. (2015). Cell wall metabolism in response to abiotic stress. Plants (Basel) 4: 112-166.

Gallaher, S.D., Fitz-Gibbon, S.T., Glaesener, A.G., Pellegrini, M., and Merchant, S.S. (2015). Chlamydomonas genome resource for laboratory strains reveals a mosaic of sequence variation, identifies true strain histories, and enables strainspecific studies. Plant Cell 27: 2335-2352.

Gallaher, S.D., Fitz-Gibbon, S.T., Strenkert, D., Purvine, S.O., Pellegrini, M., and Merchant, S.S. (2018). High-throughput sequencing of the chloroplast and mitochondrion of Chlamydomonas reinhardtii to generate improved de novo assemblies, analyze expression patterns and transcript speciation, and evaluate diversity among laboratory strains and wild isolates. The Plant Journal 93: 545565.

García-Plazaola, J.I., Fernández-Marín, B., Ferrio, J.P., Alday, J.G., Hoch, G., Landais, D., Milcu, A., Tissue, D.T., Voltas, J., Gessler, A., Roy, J., and Resco de Dios, V. (2017). Endogenous circadian rhythms in pigment composition induce changes in photochemical efficiency in plant canopies. Plant, Cell \& Environment 40: 1153-1162.

Gaskill, C., Forbes-Stovall, J., Kessler, B., Young, M., Rinehart, C.A., and Jacobshagen, S. (2010). Improved automated monitoring and new analysis algorithm for circadian phototaxis rhythms in Chlamydomonas. Plant Physiol Biochem 48: 239-246.

González-Ballester, D., Casero, D., Cokus, S., Pellegrini, M., Merchant, S.S., and Grossman, A.R. (2010). RNA-seq analysis of sulfur-deprived Chlamydomonas 
cells reveals aspects of acclimation critical for cell survival. Plant Cell 22: 20582084.

Greiner, A., Kelterborn, S., Evers, H., Kreimer, G., Sizova, I., and Hegemann, P. (2017). Targeting of photoreceptor genes in Chlamydomonas reinhardtii via zincfinger nucleases and CRISPR/Cas9. The Plant Cell 29: 2498-2518.

Harris, E.H., Stern, D.B., and Witman, G.B. eds (2009). Chapter 8 - Chlamydomonas in the Laboratory. In The Chlamydomonas Sourcebook (Second Edition) (Academic Press: London), pp. 241-302.

He, S. et al. (2020). The structural basis of Rubisco phase separation in the pyrenoid. Nature Plants 6: 1480-1490.

Holub, O., Seufferheld, M.J., Gohlke, C., Govindjee, Heiss, G.J., and Clegg, R.M. (2007). Fluorescence lifetime imaging microscopy of Chlamydomonas reinhardtii: non-photochemical quenching mutants and the effect of photosynthetic inhibitors on the slow chlorophyll fluorescence transient. J Microsc 226: 90-120.

Hyams, J. and Davies, D.R. (1972). The induction and characterisation of cell wall mutants of Chlamydomonas reinhardtii. Mutation Research/Fundamental and Molecular Mechanisms of Mutagenesis 14: 381-389.

Itakura, A.K. et al. (2019). A Rubisco-binding protein is required for normal pyrenoid number and starch sheath morphology in Chlamydomonas reinhardtii. PNAS 116: $18445-18454$.

Ivanov, I.N., Zachleder, V., Vítová, M., Barbosa, M.J., and Bišová, K. (2021). Starch production in Chlamydomonas reinhardtii through supraoptimal temperature in a pilot-scale photobioreactor. Cells 10: 1084.

Jiang, X. and Stern, D. (2009). Mating and tetrad separation of Chlamydomonas reinhardtii for genetic analysis. J Vis Exp: 1274.

Karpowicz, S.J., Prochnik, S.E., Grossman, A.R., and Merchant, S.S. (2011). The GreenCut2 resource, a phylogenomically derived inventory of proteins specific to the plant lineage. J Biol Chem 286: 21427-21439.

Lamb, J.J., Røkke, G., and Hohmann-Marriott, M.F. (2018). Chlorophyll fluorescence emission spectroscopy of oxygenic organisms at 77 K. Photosynthetica 56: 105124.

Lee, J.-H., Waffenschmidt, S., Small, L., and Goodenough, U. (2007). Betweenspecies analysis of short-repeat modules in cell wall and sex-related hydroxyproline-rich glycoproteins of Chlamydomonas. Plant Physiology 144: 1813-1826. 
Légeret, B., Schulz-Raffelt, M., Nguyen, H.M., Auroy, P., Beisson, F., Peltier, G., Blanc, G., and Li-Beisson, Y. (2016). Lipidomic and transcriptomic analyses of Chlamydomonas reinhardtii under heat stress unveil a direct route for the conversion of membrane lipids into storage lipids. Plant, Cell \& Environment 39: 834-847.

Li, L., Peng, H., Tan, S., Zhou, J., Fang, Z., Hu, Z., Gao, L., Li, T., Zhang, W., and Chen, L. (2020). Effects of early cold stress on gene expression in Chlamydomonas reinhardtii. Genomics 112: 1128-1138.

Li, X. et al. (2019). A genome-wide algal mutant library and functional screen identifies genes required for eukaryotic photosynthesis. Nat Genet 51: 627-635.

Li, X., Zhang, R., Patena, W., Gang, S.S., Blum, S.R., Ivanova, N., Yue, R., Robertson, J.M., Lefebvre, P.A., Fitz-Gibbon, S.T., Grossman, A.R., and Jonikas, M.C. (2016). An indexed, mapped mutant library enables reverse genetics studies of biological processes in Chlamydomonas reinhardtii. The Plant Cell 28: 367-387.

Li-Beisson, Y., Beisson, F., and Riekhof, W. (2015). Metabolism of acyl-lipids in Chlamydomonas reinhardtii. Plant J 82: 504-522.

Lucker, B.F., Panchy, N.L., Temple, J.A., Benning, U.F., Bibik, J.D., Neofotis, P.G., Weissman, J.C., Baxter, I.R., Shiu, S.-H., and Kramer, D.M. (2021). Selectionenriched genomic loci (SEGL) reveals genetic loci for environmental adaptation and photosynthetic productivity in Chlamydomonas reinhardtii.

Mackinder, L.C.M. et al. (2016). A repeat protein links Rubisco to form the eukaryotic carbon-concentrating organelle. PNAS 113: 5958-5963.

Massoz, S., Hanikenne, M., Bailleul, B., Coosemans, N., Radoux, M., MirandaAstudillo, H., Cardol, P., Larosa, V., and Remacle, C. (2017). In vivo chlorophyll fluorescence screening allows the isolation of a Chlamydomonas mutant defective for NDUFAF3, an assembly factor involved in mitochondrial complex I assembly. The Plant Journal 92: 584-595.

Matsuo, T. and Ishiura, M. (2010). New insights into the circadian clock in Chlamydomonas. Int Rev Cell Mol Biol 280: 281-314.

Maul, J.E., Lilly, J.W., Cui, L., dePamphilis, C.W., Miller, W., Harris, E.H., and Stern, D.B. (2002). The Chlamydomonas reinhardtii plastid chromosome. Plant Cell 14: 2659-2679.

Maxwell, K. and Johnson, G.N. (2000). Chlorophyll fluorescence-a practical guide. Journal of Experimental Botany 51: 659-668.

Merchant, S.S. et al. (2007). The Chlamydomonas genome reveals the evolution of key animal and plant functions. Science 318: 245-250. 
Mettler, T. et al. (2014). Systems analysis of the response of photosynthesis, metabolism, and growth to an increase in irradiance in the photosynthetic model organism Chlamydomonas reinhardtii. The Plant Cell 26: 2310-2350.

Meyer, M.T., Itakura, A.K., Patena, W., Wang, L., He, S., Emrich-Mills, T., Lau, C.S., Yates, G., Mackinder, L.C.M., and Jonikas, M.C. (2020). Assembly of the algal $\mathrm{CO}_{2}$-fixing organelle, the pyrenoid, is guided by a Rubisco-binding motif. Science Advances 6: eabd2408.

Minagawa, J. and Tokutsu, R. (2015). Dynamic regulation of photosynthesis in Chlamydomonas reinhardtii. Plant J 82: 413-428.

Morales, A. and Kaiser, E. (2020). Photosynthetic acclimation to fluctuating irradiance in plants. Frontiers in Plant Science 11: 268.

Mukherjee, A., Lau, C.S., Walker, C.E., Rai, A.K., Prejean, C.I., Yates, G., EmrichMills, T., Lemoine, S.G., Vinyard, D.J., Mackinder, L.C.M., and Moroney, J.V. (2019). Thylakoid localized bestrophin-like proteins are essential for the $\mathrm{CO}_{2}$ concentrating mechanism of Chlamydomonas reinhardtii. PNAS 116: 1691516920.

Müller, P., Li, X.-P., and Niyogi, K.K. (2001). Non-photochemical quenching. A response to excess light energy. Plant Physiol. 125: 1558-1566.

Muranaka, T. and Oyama, T. (2016). Heterogeneity of cellular circadian clocks in intact plants and its correction under light-dark cycles. Sci Adv 2: e1600500.

Park, J.-J., Wang, H., Gargouri, M., Deshpande, R.R., Skepper, J.N., Holguin, F.O., Juergens, M.T., Shachar-Hill, Y., Hicks, L.M., and Gang, D.R. (2015). The response of Chlamydomonas reinhardtii to nitrogen deprivation: a systems biology analysis. Plant J 81: 611-624.

Perlaza, K., Toutkoushian, H., Boone, M., Lam, M., Iwai, M., Jonikas, M.C., Walter, P., and Ramundo, S. (2019). The Mars1 kinase confers photoprotection through signaling in the chloroplast unfolded protein response. eLife 8: e49577.

Picariello, T., Hou, Y., Kubo, T., McNeill, N.A., Yanagisawa, H.-A., Oda, T., and Witman, G.B. (2020). TIM, a targeted insertional mutagenesis method utilizing CRISPR/Cas9 in Chlamydomonas reinhardtii. PLoS One 15: e0232594.

Porra, R.J., Thompson, W.A., and Kriedemann, P.E. (1989). Determination of accurate extinction coefficients and simultaneous equations for assaying chlorophylls $a$ and $b$ extracted with four different solvents: verification of the concentration of chlorophyll standards by atomic absorption spectroscopy. Biochimica et Biophysica Acta (BBA) - Bioenergetics 975: 384-394.

Pröschold, T., Harris, E.H., and Coleman, A.W. (2005). Portrait of a species: Chlamydomonas reinhardtii. Genetics 170: 1601-1610. 
Rühle, T., Reiter, B., and Leister, D. (2018). Chlorophyll fluorescence video imaging: A versatile tool for identifying factors related to photosynthesis. Front Plant Sci 9.

Sager, R. (1955). Inheritance in the green alga Chlamydomonas reinhardtii. Genetics 40: 476-489.

Salomé, P.A. and Merchant, S.S. (2021). Co-expression networks in Chlamydomonas reveal significant rhythmicity in batch cultures and empower gene function discovery. Plant Cell 33: 1058-1082.

Schmollinger, S. et al. (2014). Nitrogen-sparing mechanisms in Chlamydomonas affect the transcriptome, the proteome, and photosynthetic metabolism. The Plant Cell 26: $1410-1435$.

Schroda, M., Hemme, D., and Mühlhaus, T. (2015). The Chlamydomonas heat stress response. Plant J 82: 466-480.

Schulze, T., Prager, K., Dathe, H., Kelm, J., Kiessling, P., and Mittag, M. (2010). How the green alga Chlamydomonas reinhardtii keeps time. Protoplasma 244: 3-14.

Scranton, M.A., Ostrand, J.T., Fields, F.J., and Mayfield, S.P. (2015). Chlamydomonas as a model for biofuels and bio-products production. Plant $\mathrm{J} \mathbf{8 2}$ : 523-531.

Shimogawara, K., Fujiwara, S., Grossman, A., and Usuda, H. (1998). High-efficiency transformation of Chlamydomonas reinhardtii by electroporation. Genetics 148: 1821-1828.

Shrager, J., Hauser, C., Chang, C.-W., Harris, E.H., Davies, J., McDermott, J., Tamse, R., Zhang, Z., and Grossman, A.R. (2003). Chlamydomonas reinhardtii genome project. A guide to the generation and use of the cDNA information. Plant Physiology 131: 401-408.

Strenkert, D., Schmollinger, S., Gallaher, S.D., Salomé, P.A., Purvine, S.O., Nicora, C.D., Mettler-Altmann, T., Soubeyrand, E., Weber, A.P.M., Lipton, M.S., Basset, G.J., and Merchant, S.S. (2019). Multiomics resolution of molecular events during a day in the life of Chlamydomonas. Proc Natl Acad Sci USA 116: 2374-2383.

Terashima, M., Specht, M., and Hippler, M. (2011). The chloroplast proteome: a survey from the Chlamydomonas reinhardtii perspective with a focus on distinctive features. Curr Genet 57: 151-168.

Urzica, E.I., Casero, D., Yamasaki, H., Hsieh, S.I., Adler, L.N., Karpowicz, S.J., Blaby-Haas, C.E., Clarke, S.G., Loo, J.A., Pellegrini, M., and Merchant, S.S. (2012). Systems and trans-system level analysis identifies conserved iron deficiency responses in the plant lineage. Plant Cell 24: 3921-3948. 
Vilarrasa-Blasi, J. et al. (2020). Systematic characterization of gene function in a photosynthetic organism.

Wakao, S. et al. (2021). Discovery of photosynthesis genes through whole-genome sequencing of acetate-requiring mutants of Chlamydomonas reinhardtii. PLOS Genetics 17: e1009725.

Wang, L., Yang, L., Wen, X., Chen, Z., Liang, Q., Li, J., and Wang, W. (2019). Rapid and high efficiency transformation of Chlamydomonas reinhardtii by square-wave electroporation. Biosci Rep 39: BSR20181210.

Wang, X., Chen, Z., Li, Q., Zhang, J., Liu, S., and Duan, D. (2018). High-density SNPbased QTL mapping and candidate gene screening for yield-related blade length and width in Saccharina japonica (Laminariales, Phaeophyta). Sci Rep 8: 13591.

Wellburn, A.R. (1994). The spectral determination of chlorophylls a and b, as well as total carotenoids, using various solvents with spectrophotometers of different resolution. Journal of Plant Physiology 144: 307-313.

Wu, J. et al. (2018). QTL mapping of fiber-related traits based on a high-density genetic map in flax (Linum usitatissimum L.). Frontiers in Plant Science 9: 885.

Xu, Q., Xu, X., Shi, Y., Xu, J., and Huang, B. (2014). Transgenic tobacco plants overexpressing a grass PpEXP1 gene exhibit enhanced tolerance to heat stress. PLOS ONE 9: e100792.

Xu, Y., Li, P., Yang, Z., and Xu, C. (2017). Genetic mapping of quantitative trait loci in crops. The Crop Journal 5: 175-184.

Yamano, T., Toyokawa, C., Shimamura, D., Matsuoka, T., and Fukuzawa, H. (2021). CO2-dependent migration and relocation of LCIB, a pyrenoid-peripheral protein in Chlamydomonas reinhardtii. Plant Physiology: kiab528.

Zachleder, V., Ivanov, I., Vítová, M., and Bišová, K. (2019). Cell cycle arrest by supraoptimal temperature in the alga Chlamydomonas reinhardtii. Cells 8: 1237.

Zhan, Y. et al. (2018). Pyrenoid functions revealed by proteomics in Chlamydomonas reinhardtii. PLOS ONE 13: e0185039.

Zhang, N. et al. (2021). Systems-wide analysis revealed shared and unique responses to moderate and acute high temperatures in the green alga Chlamydomonas reinhardtii.

Zhang, R., Patena, W., Armbruster, U., Gang, S.S., Blum, S.R., and Jonikas, M.C. (2014). High-throughput genotyping of green algal mutants reveals random distribution of mutagenic insertion sites and endonucleolytic cleavage of transforming DNA. The Plant Cell 26: 1398-1409. 
bioRxiv preprint doi: https://doi.org/10.1101/2022.01.15.476454; this version posted January 17,2022 . The copyright holder for this preprint (which was not certified by peer review) is the author/funder, who has granted bioRxiv a license to display the preprint in perpetuity. It is made available under aCC-BY-NC-ND 4.0 International license.

Zones, J.M., Blaby, I.K., Merchant, S.S., and Umen, J.G. (2015). High-resolution profiling of a synchronized diurnal transcriptome from Chlamydomonas reinhardtii reveals continuous cell and metabolic differentiation. The Plant Cell 27: 27432769 . 


\section{Figure 1}
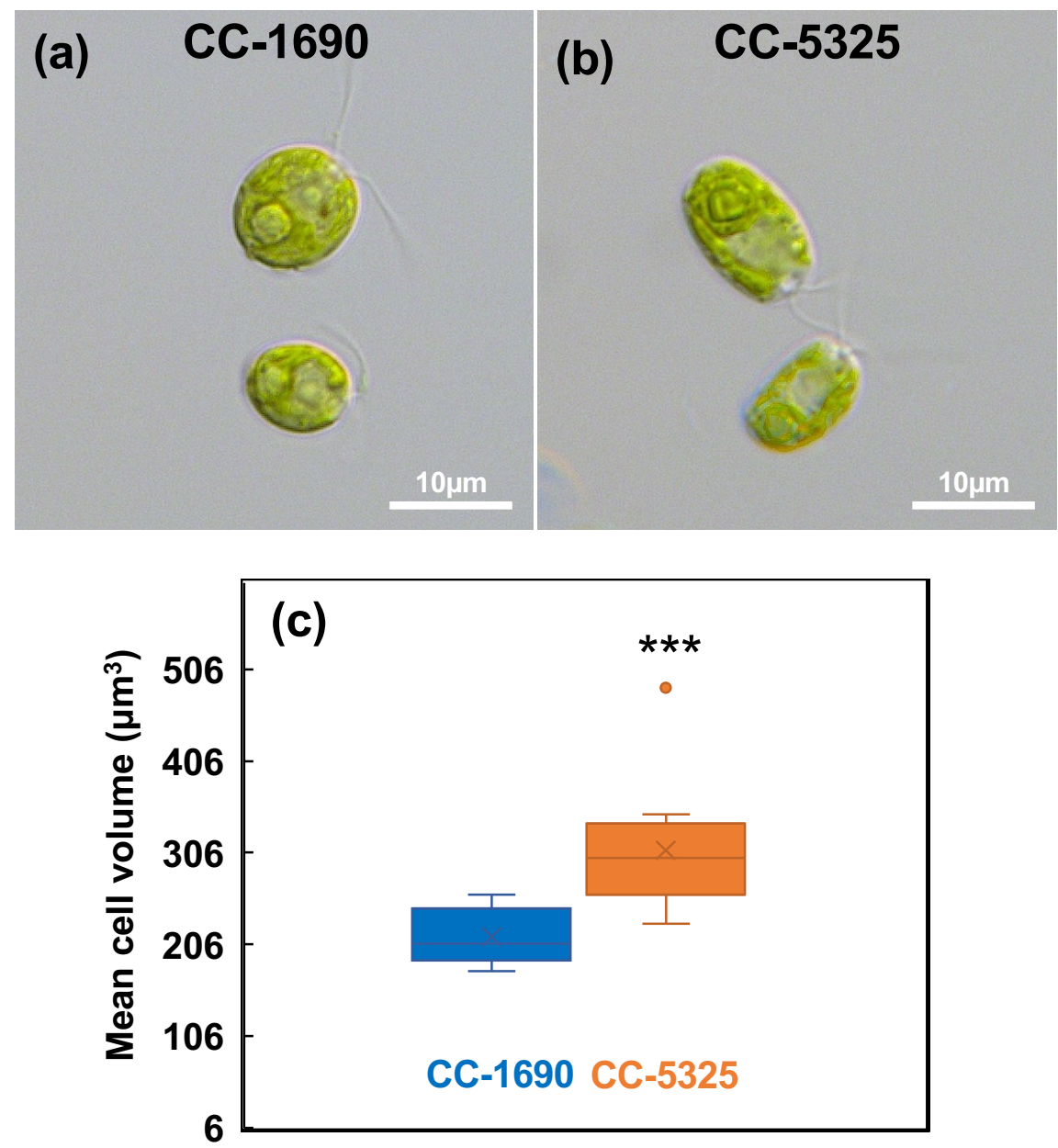
Figure 2

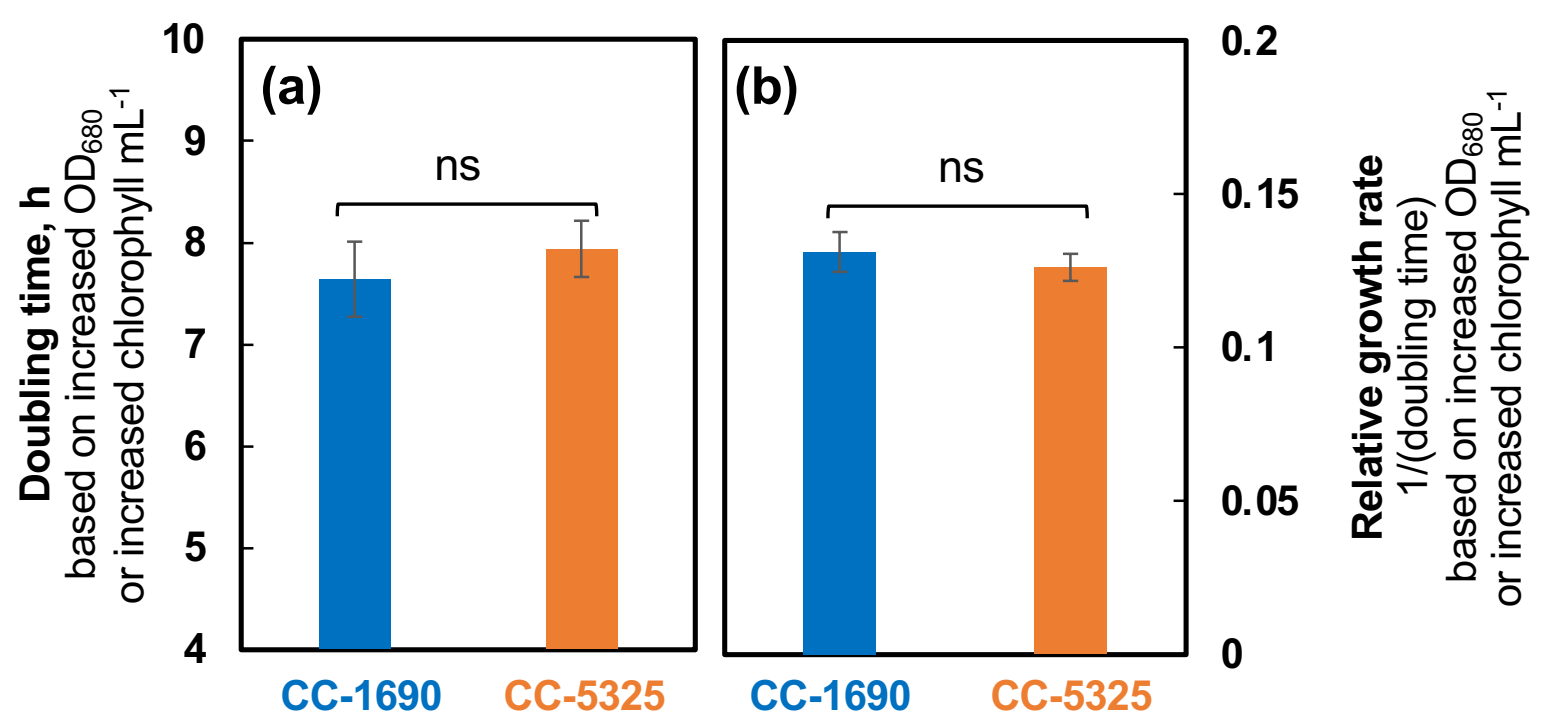


Figure 3

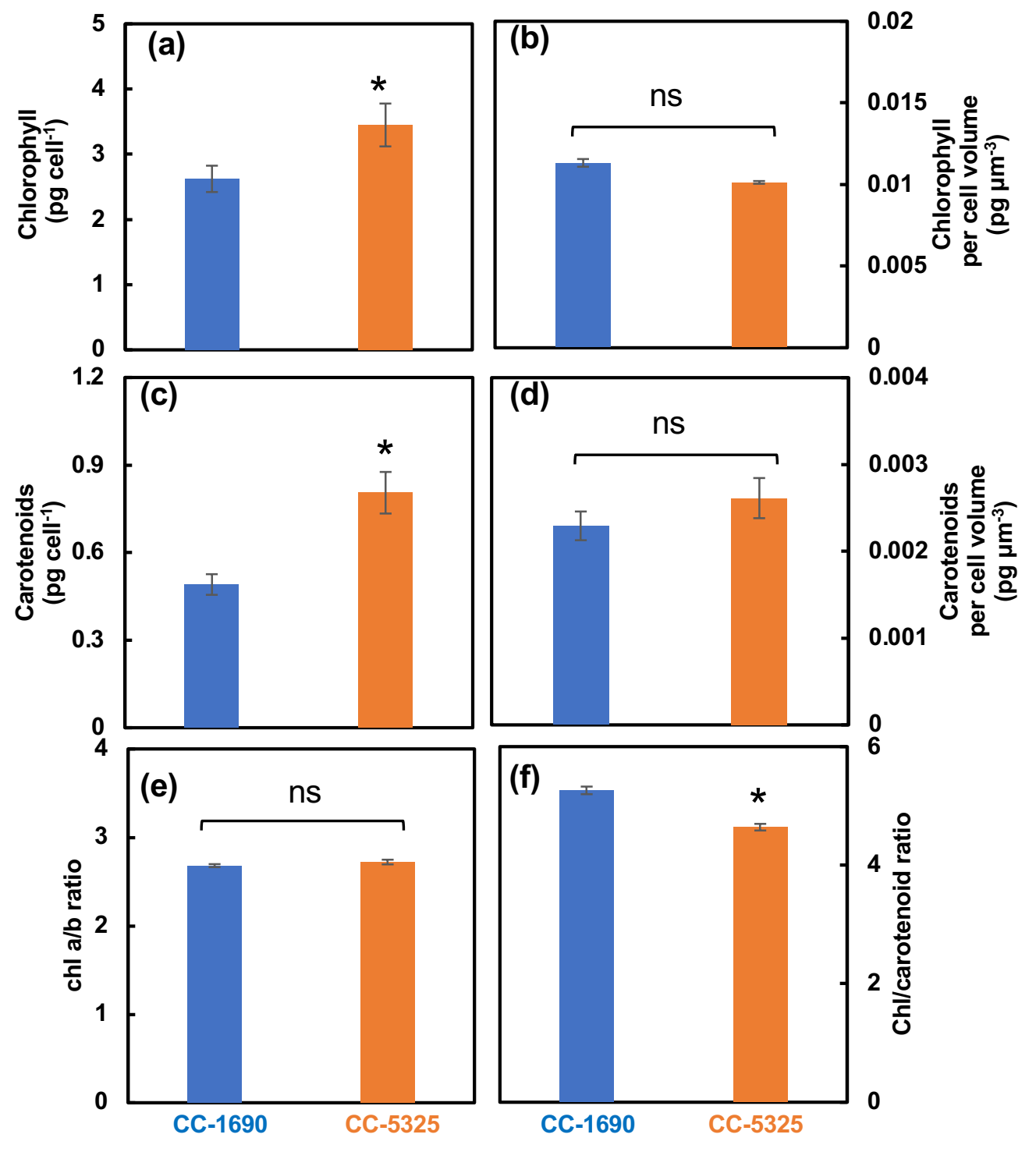




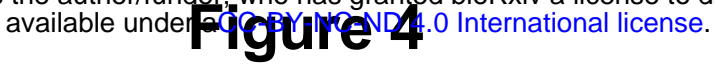

(a)

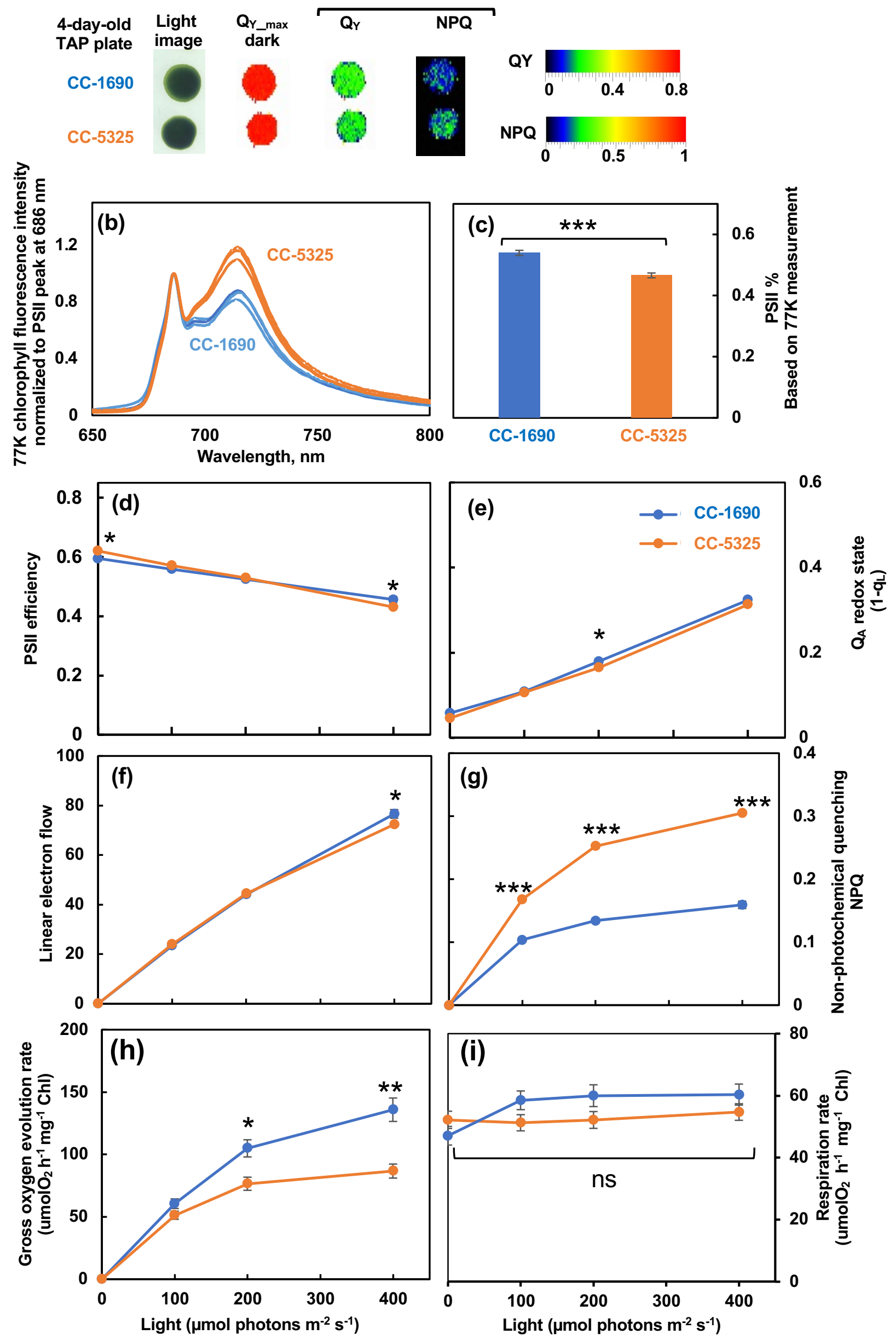




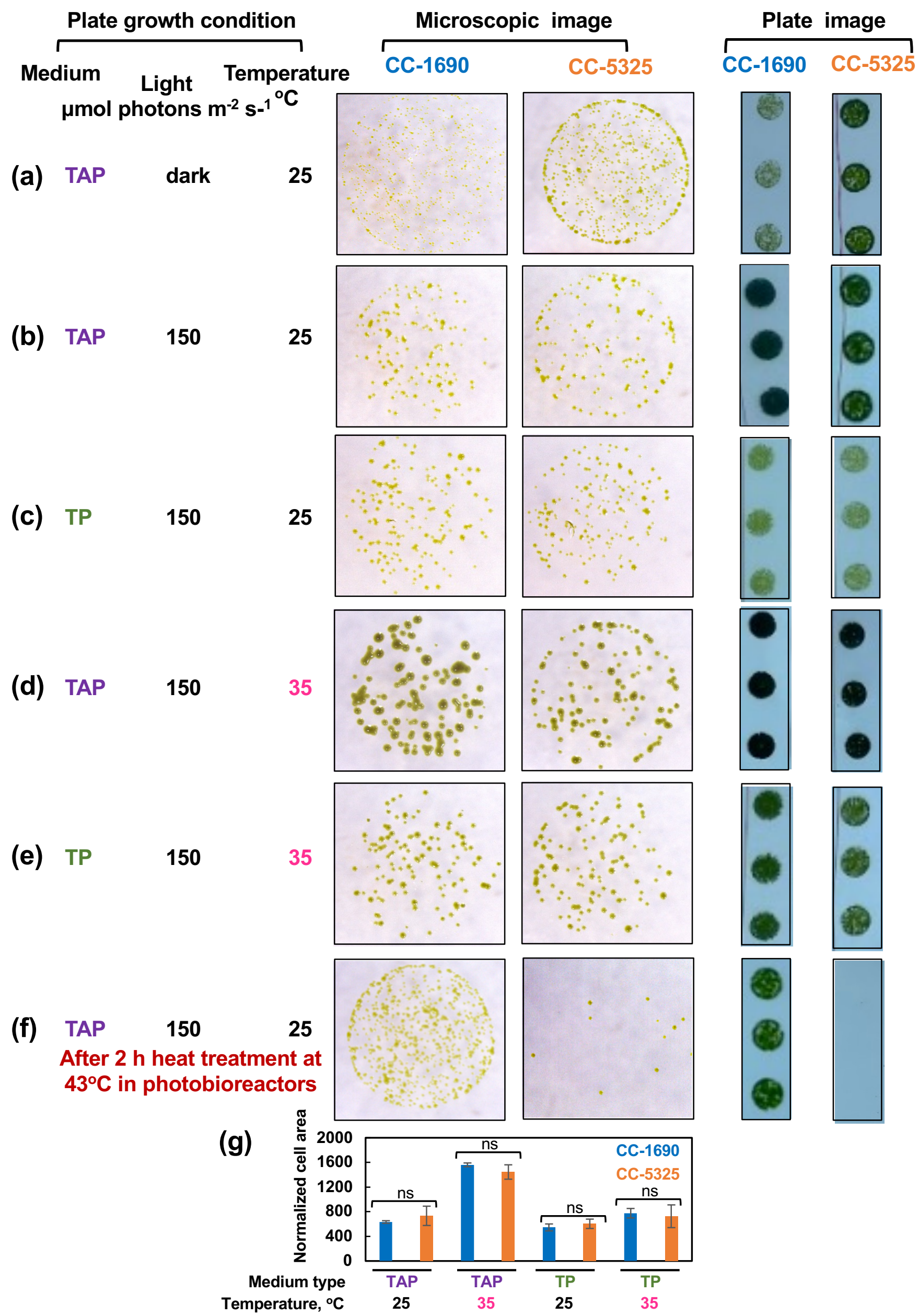




\section{Figure 6}
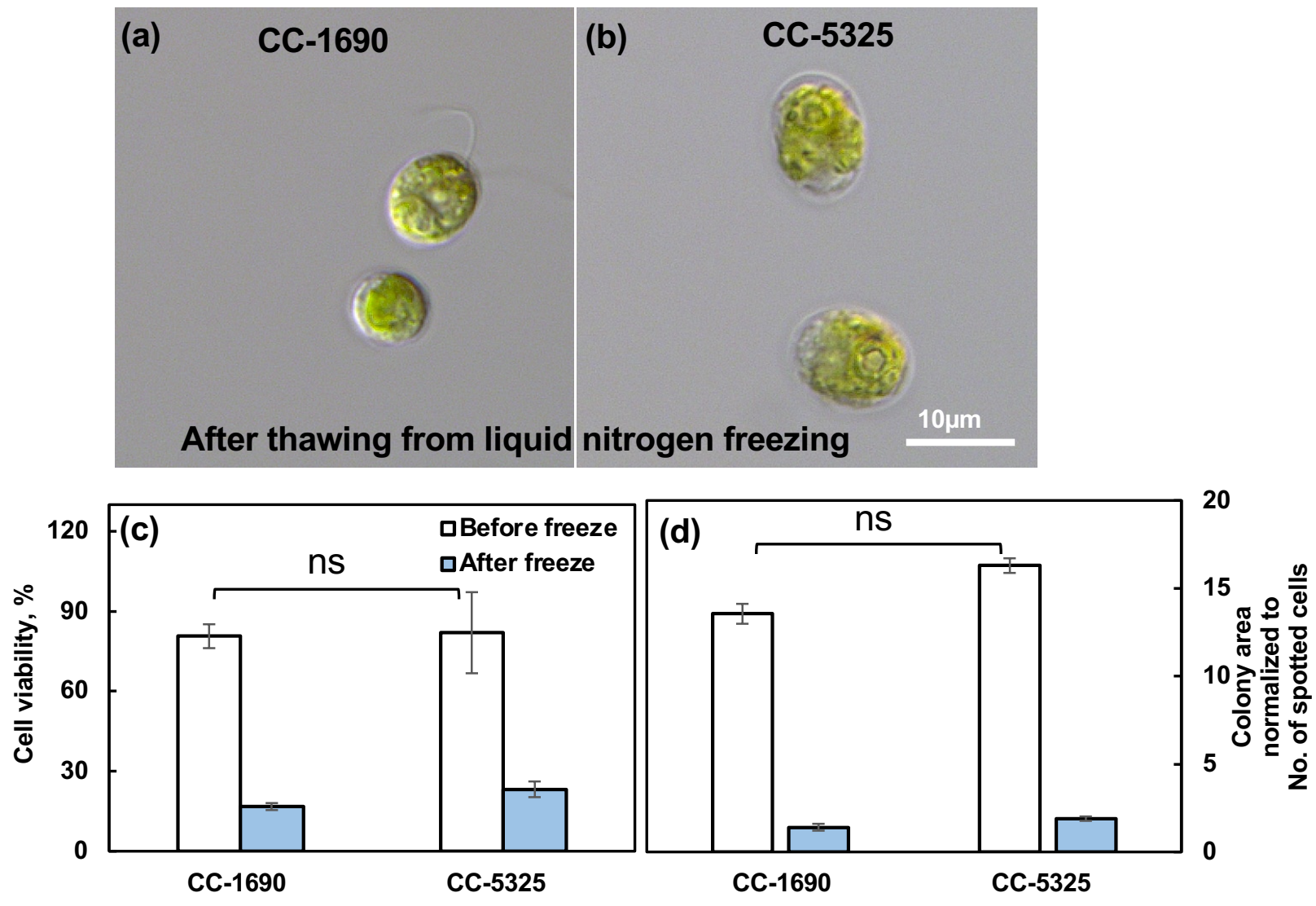
Figure 7

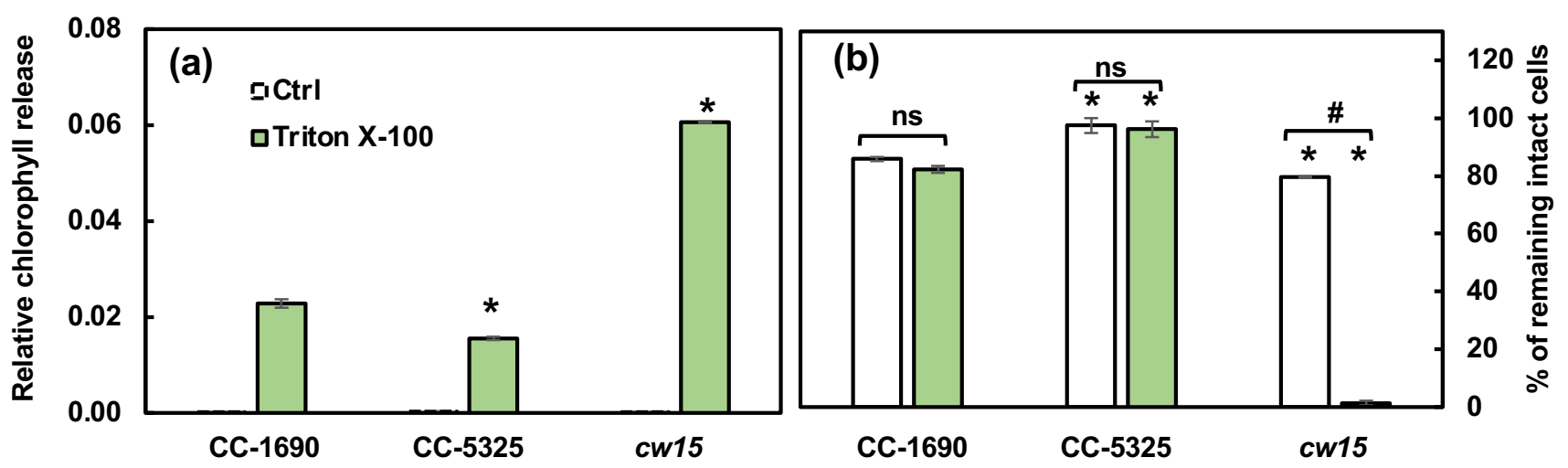


Figure 8

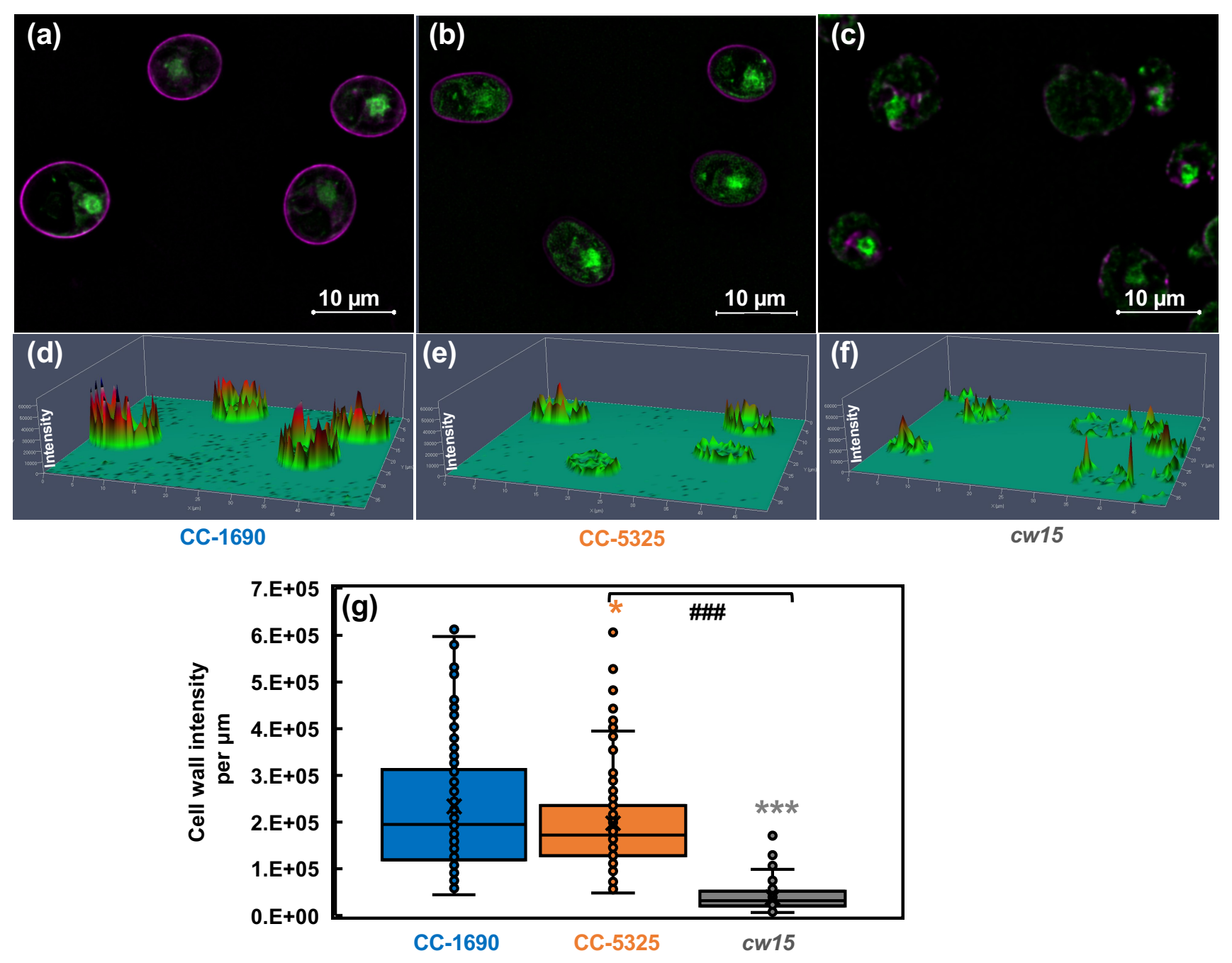


Figure 9

Constant darkness
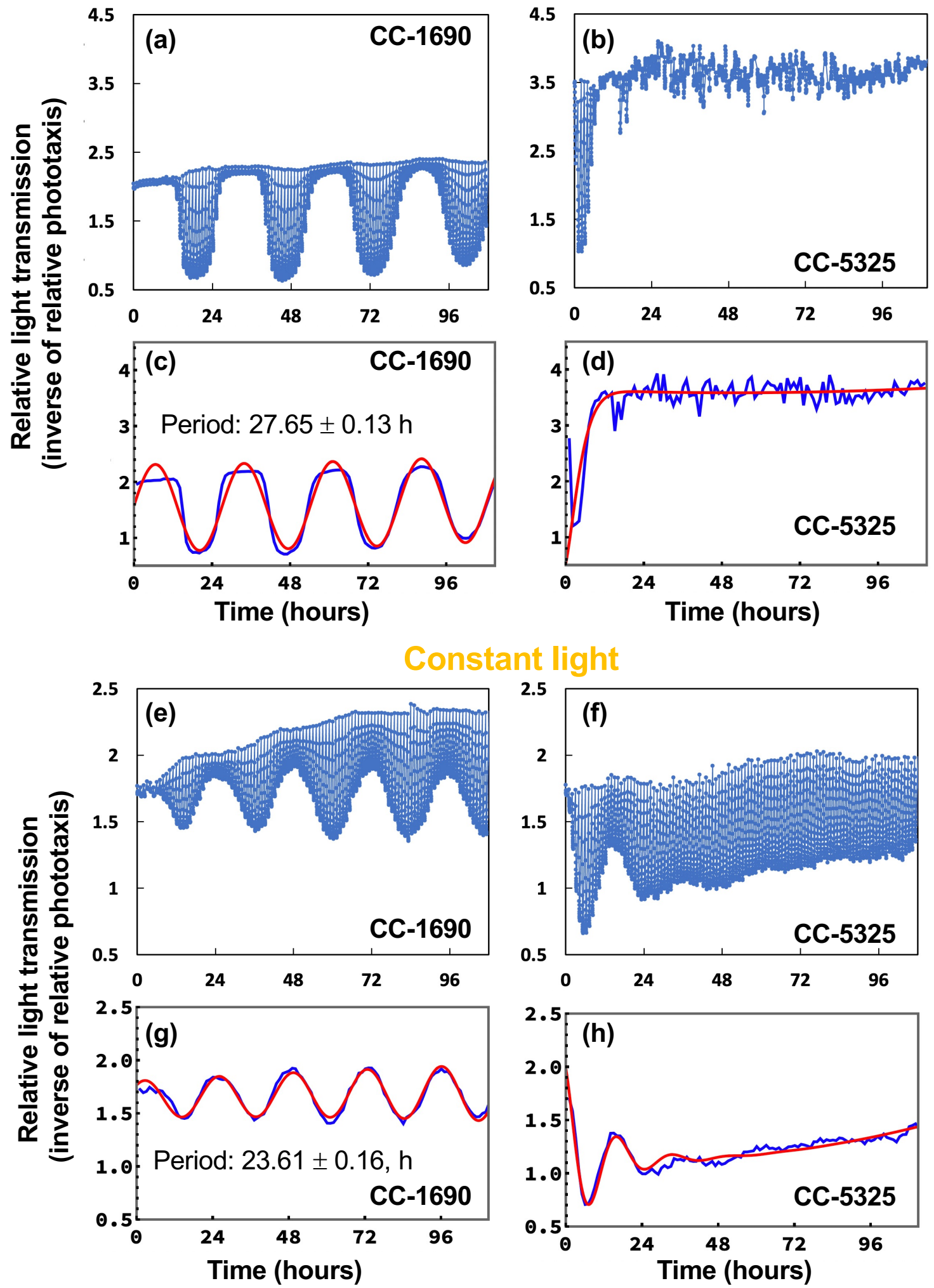
Table 1

\begin{tabular}{|c|c|c|}
\hline & CC-1690 & CC-5325 \\
\hline Other names & $21 g r$ & $\begin{array}{l}\text { CMJ030, CC-4533, } \\
\text { CLiP background }\end{array}$ \\
\hline Cell volume & & Larger \\
\hline $\begin{array}{c}\text { Growth in PBRs, TAP, } \\
100 \mu \mathrm{mol} \text { photons } \mathrm{m}^{-2} \mathrm{~s}-{ }^{-1} \text { light, air, } 25^{\circ} \mathrm{C}\end{array}$ & \multicolumn{2}{|c|}{ Similar } \\
\hline Chlorophyll and carotenoid per cell & & Greater \\
\hline Chlorophyll and carotenoid per cell volume & \multicolumn{2}{|c|}{ Similar } \\
\hline Chlorophyll a/b ratio & \multicolumn{2}{|c|}{ Similar } \\
\hline Chlorophyll/carotenoid ratio & & Smaller \\
\hline PSII antenna size & & Smaller \\
\hline $\begin{array}{l}\text { Non-photochemical quenching } \\
\text { NPQ }\end{array}$ & & Increased \\
\hline Gross $\mathrm{O}_{2}$ evolution rates & & $\begin{array}{l}\text { Smaller at or above } 200 \\
\mu \mathrm{mol} \text { photons } \mathrm{m}^{-2} \mathrm{~s}^{-1} \text { light }\end{array}$ \\
\hline Respiration rates & \multicolumn{2}{|c|}{ Similar } \\
\hline Heterotrophic growth in dark on plates & & Faster \\
\hline $\begin{array}{l}\text { Mixotrophic and photoautotrophic growth } \\
\text { on plates }\left(150 \mu \mathrm{mol} \text { photons } \mathrm{m}^{-2} \mathrm{~s}^{-1} \text { light, }\right. \\
\left.\text { air, } 25 \text { or } 35^{\circ} \mathrm{C}\right)\end{array}$ & \multicolumn{2}{|c|}{ Similar } \\
\hline Sensitivity to $43^{\circ} \mathrm{C}$ in PBRs & & Greater \\
\hline Freezing tolerance & \multicolumn{2}{|c|}{ Similar } \\
\hline Detergent tolerance & \multicolumn{2}{|c|}{ Similar } \\
\hline Cell wall integrity & \multicolumn{2}{|c|}{ Similar } \\
\hline Cell wall fluorescence intensity & & Reduced \\
\hline $\begin{array}{l}\text { Circadian rhythm of phototaxis } \\
\text { in constant darkness or constant light }\end{array}$ & Yes & No \\
\hline
\end{tabular}

